\title{
IMPACTOS DA GERAÇÃO DISTRIBUÍDA FOTOVOLTAICA E DA TARIFA BRANCA NO CONSUMO DO SETOR RESIDENCIAL
}

\section{IMPACTS OF THE PHOTOVOLTAIC DISTRIBUTED GENERATION AND OF THE WHITE ENERGY TARIFF ON ELECTRICITY CONSUMPTION OF THE RESIDENTIAL SECTOR}

\author{
Matheus Gomes Rodrigues ${ }^{1}$ \\ Universidade Federal de Viçosa, Viçosa, MG, Brasil, matheus.g.gomes@ufv.br \\ Joyce Correna Carlo² \\ Universidade Federal de Viçosa, Viçosa, MG, Brasil, joycecarlo@ufv.br
}

\begin{abstract}
Resumo
Desde o início deste século, nota-se uma crescente necessidade de suprimento energético e consequentemente o aumento das preocupações ambientais internacionais. Em resposta a essa demanda, a geração distribuída fotovoltaica surge como possibilidade de redução das emissões de gases de efeito estufa, além da redução do investimento em produção, transmissão ou distribuição. Outra forma de controle referente ao consumo energético é por meio do gerenciamento pelo lado da demanda que, no Brasil, surge como opção para o setor residencial com a tarifa Branca. Porém, a inserção destas estratégias, assim como a mudança para o novo regime tarifário, requer investimentos e planejamento, os quais devem ser cuidadosamente analisados. Nesse contexto, as simulações computacionais possibilitam visualizar possíveis cenários, facilitar análises e fomentar planejamentos futuros. Este trabalho avalia os efeitos da geração distribuída fotovoltaica e do novo regime tarifário para consumidores residenciais que aderirem à tarifa Branca. Unidades habitacionais localizadas em Bento Gonçalves, São Paulo e Belém, com ou sem geração fotovoltaica, foram estudadas. Mostra-se que apenas a adesão à tarifa Branca gera 12,7\%, 17,1\%, 23,4\% de aumento de gastos nas respectivas localidades, o que ressalta a necessidade da mudança nos hábitos atualmente típicos do consumidor e da redução no uso de energia nos horários de pico. Em contrapartida, os casos com geração fotovoltaica foram majoritariamente mais econômicos com a tarifa Convencional. No entanto, houve casos com resultado contrário em Bento Gonçalves, onde a diferença não foi relevante ou a melhor opção foi a tarifa Branca, visto que o pico de consumo gerado pelo chuveiro elétrico foi eliminado com a inserção do sistema solar de aquecimento de água que acompanhou o sistema fotovoltaico. Este, por sua vez, levou o consumo das habitações à tarifa mínima, principalmente em São Paulo, onde os custos foram praticamente os mesmos, não importando o regime tarifário escolhido.
\end{abstract}

Palavras-chave: Simulação. Tarifa branca. Geração distribuída. Fotovoltaico.

\begin{abstract}
Since the beginning of this century, there has been an increasing need for energy supply and, consequently, an increase in international environmental concerns. In response to this demand, photovoltaic distributed generation appears as a possibility of reducing greenhouse gas emissions, as well as reducing investment in production, transmission, or distribution. Another form of control related to energy consumption is through management by the demand side, which in Brazil is an option for the residential sector with the new energy tariff, called white energy tariff. However, inserting these strategies and changing the new tariff regime requires investment and planning, which must be carefully analyzed. Computer simulations allow visualizing possible scenarios, facilitating the analysis, and encouraging future planning in this context. This paper assesses the effects of distributed photovoltaic genera tion and the new tariff regime of residential consumers that adhere to the white energy tariff. We studied housing units located in Bento Gonçalves, São Paulo, and Belém, with or without photovoltaic generation. We showed that only adherence to the white energy tariff generates a cost increase of $12.7 \%, 17.1 \%, 23.4 \%$ in the respective localities, which highlights, on the one hand, the need to change the typical consumer habits by reducing the use of electricity at peak times. On the other hand, cases with photovoltaic generation were more cost-effective with Conventional Tariff. Nevertheless, we observed Bento Gonçalves, where the difference was not significant. The best option was the white energy tariff because the peak consumption generated by the electric shower was removed by the insertion of a solar water heating installed with the photovoltaic system. In turn, this action led the dwellings to consume the minimum tariff, especially in São Paulo, where costs were equivalent regardless of the chosen tariff regime.
\end{abstract}

Keywords: Simulation. White energy tariff. Distributed generation. Photovoltaic.

How to cite this article:

RODRIGUES, M. G.; CARLO, J. C. Impactos da geração distribuída fotovoltaica e da tarifa branca no consumo do setor residencial. PARC Pesquisa em Arquitetura e Construção, v. 11, p. e020018, 24 set. 2020.

DOI:https://doi.org/10.20396/parc.v11i0.8655498.

Received in 06.06.2019 - accepted in 21.07.2020 - published 24.09.2020

e020018-1 | PARC Pesq. em Arquit. e Constr., Campinas, SP, v. 11, p. e020018, 2020, ISSN 1980-6809 


\section{Introdução}

De maneira global, prevê-se que a capacidade de geração de energia solar fotovoltaica distribuída aumente mais de $250 \%$, podendo atingir $530 \mathrm{GW}$ até 2024 , em comparação com o período de seis anos anterior, a expansão mais do que duplica (IEA, 2019). Segundo a Renewable Energy Policy Network for the 21st Century (REN21, 2019), o mercado global anual de energia solar fotovoltaica (PV) aumentou apenas ligeiramente em 2018, mas o suficiente para superar o nível de $100 \mathrm{GW}$ pela primeira vez. E apesar da taxa de crescimento de um dígito do mercado global em 2018, a energia solar fotovoltaica se tornou a tecnologia de energia de crescimento mais rápido no mundo. A demanda por energia solar fotovoltaica está se espalhando e se expandindo à medida que se torna a opção mais competitiva para geração de eletricidade.

Viana, Manassero Junior e Udaeta (2018) afirmam que este aumento exponencial mundial se deve a inúmeros fatores, entre eles a redução de custos para instalação do sistema e as políticas de incentivo dadas pelos governos, por meio de regulamentações da energia gerada pelo consumidor. Este crescimento vem ocorrendo em duas direções: sistemas fotovoltaicos instalados principalmente nos telhados de unidades consumidoras residenciais e investimento de grandes empresas na construção de usinas solares (SOUTO et al., 2018).

Segundo Tenfen et al. (2013), os principais instrumentos utilizados nas políticas de incentivos para a microgeração de energia e a inserção das fontes renováveis no mundo são: tarifa prêmio (Feed-in Tariffs), subsídios financeiros, incentivos fiscais, certificados verdes de energia renovável, sistema de cotas com certificados verdes e sistema de compensação de energia (Net Metering). Estes incentivos podem ser divididos em políticas regulatórias, incentivos financeiros e financiamento público.

O novo cenário de expansão do sistema elétrico considera integrar várias pequenas gerações no que é chamado de Geração Distribuída (GD), em que cada unidade geradora fornece energia elétrica em um local mais próximo do consumidor, eliminando, por exemplo, os custos com longas linhas de transmissão e distribuição (TENFEN et al., 2013). As microrredes são o conjunto desse tipo de geração e de consumidores de energia elétrica que podem operar conectados e sincronizados com a rede principal.

Segundo a Aneel (2016a), entre as vantagens das microrredes bem dimensionadas, pode-se citar: a diminuição do consumo de combustíveis fósseis e, com isso, a redução das emissões de gases poluentes; a redução de custos com perdas técnicas; o adiamento de investimentos em linhas de transmissão e distribuição; a melhora da qualidade e confiabilidade do fornecimento de energia. Portanto, as microrredes em conjunto com as redes inteligentes, ou smart grids, estão emergindo como uma alternativa para satisfazer o crescimento do mercado de energia, além de novas exigências ambientais (DRUDE; PEREIRA JUNIOR; RÜTHER, 2014).

No Brasil, conforme disposto nos regulamentos da Aneel (ANEEL, 2016a), a micro e a minigeração distribuídas consistem na produção de energia elétrica a partir de pequenas centrais geradoras que utilizam fontes renováveis de energia elétrica ou cogeração qualificada, conectadas à rede de distribuição por meio de instalações de unidades consumidoras. Para efeitos de diferenciação, a microgeração distribuída refere-se a uma central geradora de energia elétrica com potência instalada menor ou igual a $75 \mathrm{~kW}$, enquanto a minigeração distribuída é limitada por centrais geradoras com potência instalada superior a $75 \mathrm{~kW}$ e menor ou igual a $3 \mathrm{MW}$, para a fonte hídrica, ou 5 MW, para as demais fontes. 
Jannuzzi e Mello (2013) mostram um potencial de geração de energia fotovoltaica (FV) no Brasil de $16 \times 1012 \mathrm{MWh}$, cujos níveis médios anuais de irradiação global variam de $1.500 \mathrm{kWh} / \mathrm{m}^{2}$ a $2.500 \mathrm{kWh} / \mathrm{m}^{2}$ (apresentando locais com níveis de irradiação solar global diária - média anual típica - de até cerca de $6.000 \mathrm{Wh} / \mathrm{m}^{2}$.dia). Estes são níveis maiores que a maioria dos países europeus, onde os investimentos neste tipo de tecnologia são bem mais difundidos. Os autores também apontam a geração FV como uma solução para momentos em que o país sofre com estações de seca, em que, normalmente, as fontes energéticas são combustíveis fósseis e/ou energia armazenada em reservatórios hidroelétricos, resultando em aumento de emissões e impactos ambientais.

Como uma forma de aumento na inserção da tecnologia FV no setor residencial, Santos e Rüther (2012) afirmam que os kits FV são uma alternativa de baixo custo, prontos para uso, para uma absorção rápida e massiva para o consumidor residencial conectado à rede. Segundo os autores, estes podem economizar tempo e custos de projeto e instalação, além de normalmente requerer apenas uma fração das áreas de cobertura individuais existentes nas unidades habitacionais e, ainda, com possibilidade de expansão.

Neste contexto, Souto et al. (2018) destacam que, antes de se pensar na instalação do sistema fotovoltaico, é de extrema importância promover ações de eficiência energética, como a substituição do chuveiro elétrico por sistemas de aquecimento solar. Ainda segundo os autores, a energia elétrica consumida pelo chuveiro elétrico no setor residencial pode chegar a até $45 \%$ da fatura mensal de energia, o que mostra o alto potencial do uso de sistemas de aquecedores solares em substituição ao chuveiro elétrico.

Outro fator favorável para a adoção de aquecedores solares é o fato de que o território brasileiro está localizado na região intertropical, que possui um alto índice de irradiação solar. A Alemanha é o líder europeu na utilização de aquecedor solar, mesmo com um clima temperado, e esta liderança foi atingida a partir de incentivos por políticas públicas. O mercado solar térmico alemão se beneficia não apenas do aumento dos preços da energia, mas também dos programas de subsídios concedidos pelo governo (VASCONCELLOS, 2012).

Diante deste quadro, Miranda, Szklo e Schaeffer (2014) contrapõem os benefícios do sistema fotovoltaico ao afirmar que a inserção destes em larga escala poderá aumentar a diferença entre o vale e o pico de geração e, consequentemente, o período de ponta poderá ser ainda maior, o que eventualmente irá tornar o sistema ainda mais caro. $\mathrm{O}$ horário de ponta comumente ocorre entre 18 h e 21 h, que é o período do dia no qual o consumo de energia elétrica é consideravelmente maior, devido à coincidência da combinação dos horários de operação do comércio e indústria com o aumento do consumo nas unidades residenciais e ao acionamento da iluminação pública.

É importante ressaltar que a Resolução Normativa 687 (ANEEL, 2015) estabelece um sistema de compensação, em que a energia ativa injetada no sistema de distribuição pela unidade consumidora será cedida, a título de empréstimo gratuito, para a distribuidora, passando a unidade consumidora a ter um crédito em quantidade de energia ativa a ser consumida por um prazo de 60 (sessenta) meses.

Miranda, Szklo e Schaeffer (2014) destacam também que, uma vez que o horário de ponta ocorre apenas em um curto período do dia, parte da capacidade de geração de energia eventualmente acaba se tornando ociosa. Assim, eles mostram uma necessidade de se identificar de forma clara as cargas elétricas utilizadas na unidade residencial e o consumo como um todo para que, assim, seja possível que o usuário 
possa realizar um gerenciamento tanto da sua geração quanto da sua demanda de energia elétrica (SOUTO et al., 2018).

Diante desta necessidade de gerenciamento pelo lado da demanda, especificamente no que concerne ao setor residencial, foi aprovada em 2011 pela Aneel um novo modelo tarifário, a tarifa Branca. Ela é uma modalidade que possibilita o deslocamento do pico e a redução do consumo de energia pelo gerenciamento da demanda. Ela sinaliza ao consumidor final a possibilidade de ser uma alternativa econômica à tarifa tradicional visto que, ao deslocar o consumo para outros horários fora do horário de pico, o usuário se beneficia economicamente (FINOTTI; ALMEIDA; ZILLES, 2018).

A tarifa Branca busca influenciar os hábitos de consumo de energia elétrica para o consumidor de baixa tensão no Brasil. Esta modalidade tarifária possibilita que o consumidor pague valores diferentes pela energia consumida de acordo com a hora e o dia da semana. As 24 horas do dia são divididas em três períodos, chamados de Fora de Ponta (FP), Intermediário (I) e de Ponta (P). A Aneel determina que um período de cinco horas deva ser utilizado para distribuir os períodos Intermediários e de Ponta, sendo que cabe a cada distribuidora escolher as cinco horas do dia que melhor se encaixam em seu pico de distribuição.

Destas, a primeira e a última hora do período são definidas como intermediárias. Entre as horas intermediárias temos o período de Ponta e as demais horas do dia são definidas como Fora de Ponta. O preço da energia no período Fora da Ponta será mais barato que o preço da energia no modelo de cobrança Convencional, nos horários Intermediários o valor cobrado será até três vezes o valor da convencional e, no período de Ponta, o valor cobrado será de até cinco vezes o da tarifa Convencional (ANEEL, 2016b).

Outra vantagem do gerenciamento pelo lado da demanda é favorecer também as concessionárias, permitindo que se minimizem as perdas do sistema, tornando-o mais eficiente. Também posterga grandes investimentos na infraestrutura da rede tanto para geração quanto para distribuição, já que o sistema como um todo é dimensionado para atender à demanda referente ao pico (PONCE-JARA et al., 2017).

Dado este cenário, é de fundamental importância ressaltar que, caso haja energia excedente num determinado período (por exemplo, no horário fora de ponta), os créditos poderão ser utilizados para abater o consumo em outro período (no horário de ponta, por exemplo). Todavia, nesse caso, a quantidade de créditos é multiplicada por uma relação de cerca de 60\% (ANEEL, 2016a). Assim, o objetivo deste trabalho é verificar se a mudança para este novo sistema de cobrança, a tarifa Branca, irá beneficiar ou prejudicar as unidades consumidoras, dado o perfil de consumo residencial e a possibilidade de geração de energia fotovoltaica.

\section{Método}

A pesquisa realizada caracteriza-se como de natureza básica, exploratória, com abordagem quantitativa, utilizando instrumentos de simulação computacional termoenergética. Foram utilizados oito modelos de unidades habitacionais representativas do setor residencial (TELLES, 2016; TEIXEIRA et. al, 2015).Telles (2016) definiu, para estes modelos, características como materiais da envoltória, percentual de abertura de fachada e área de abertura para ventilação. Os modelos utilizados são apresentados na Figura 1. 
RODRIGUES, Matheus G.; CARLO, Joyce C.

Impactos da geração distribuída fotovoltaica e da tarifa branca no consumo do setor residencial

Figura 1 - Modelos utilizados nas simulações
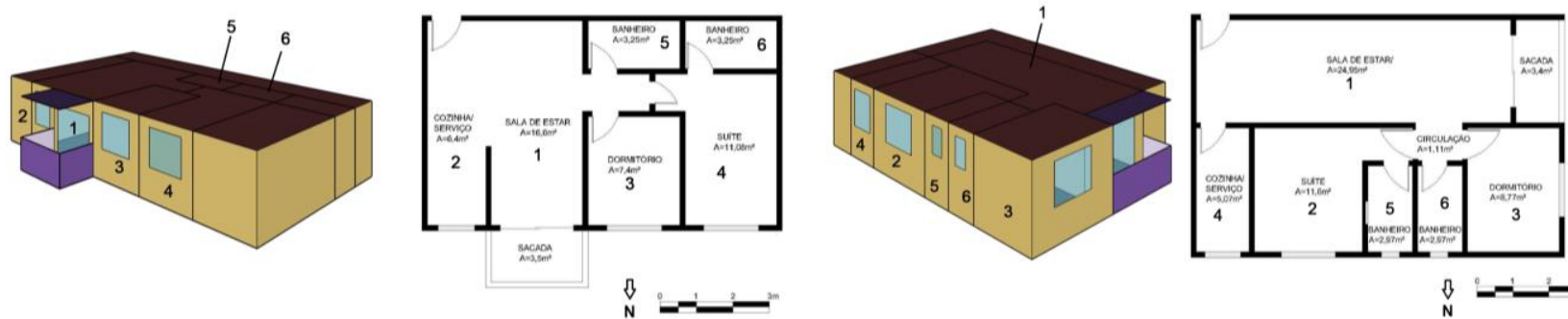

(a)

(b)
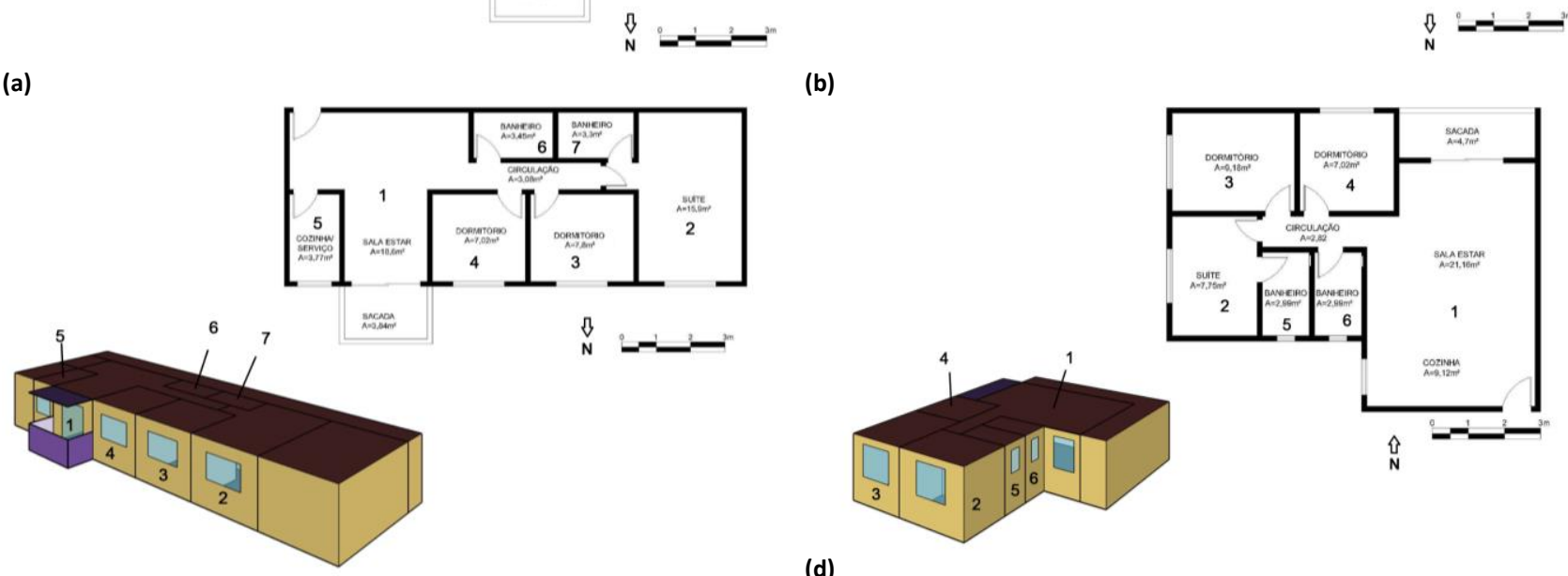

(c)
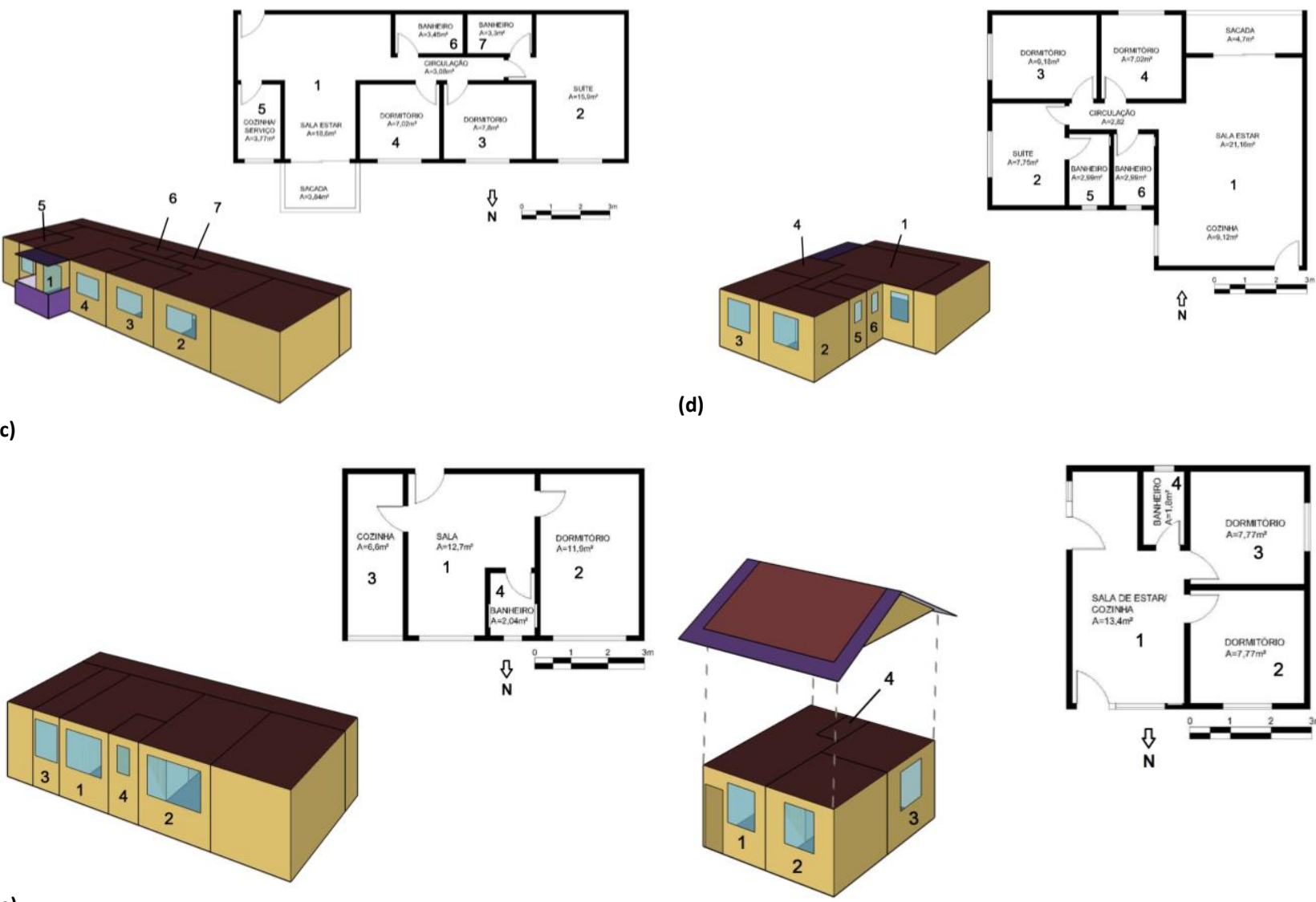

(d)
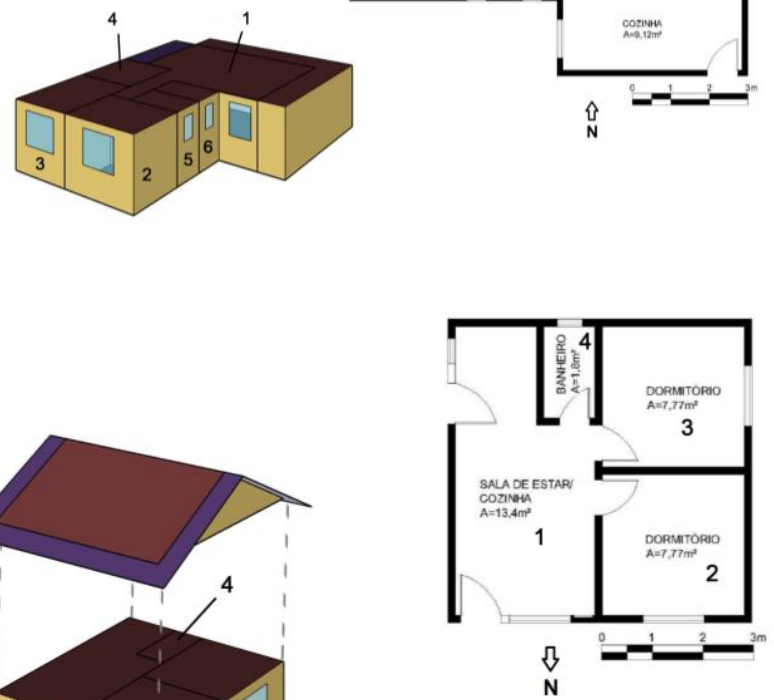

(e)

(f)

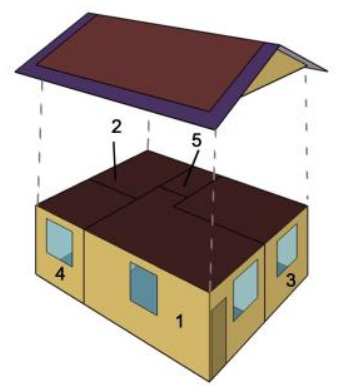

(g)

Fonte: Elaborado pelos autores.

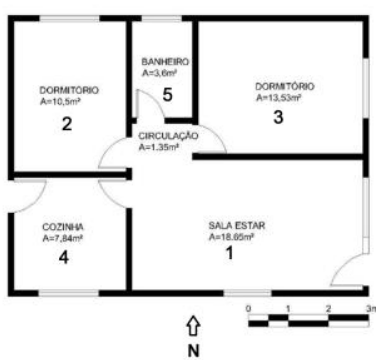

(h)

Os padrões de uso de iluminação, equipamentos e ocupação de usuários com estilos de vida tradicional e contemporâneo, aplicados neste trabalho, foram definidos no trabalho de Rodrigues, Santos e Carlo (2019), onde foi modelado o consumo energético 
de acordo com estes perfis e estes foram calibrados de acordo com as categorias de usos finais definidas por Abrahão (2015). A Figura 2 exemplifica como o consumo foi dividido no trabalho dos autores.

Figura 2 - Consumo mensal por categoria de uso final para Modelo 1 de acordo com o estilo de vida Tradicional (T) e Contem porâneo (C). (a) Bento Gonçalves (b) São Paulo (c) Belém

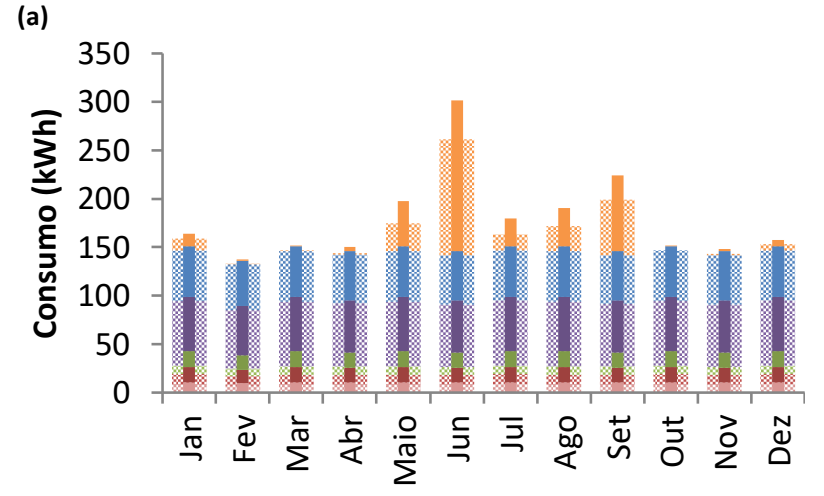

(c)

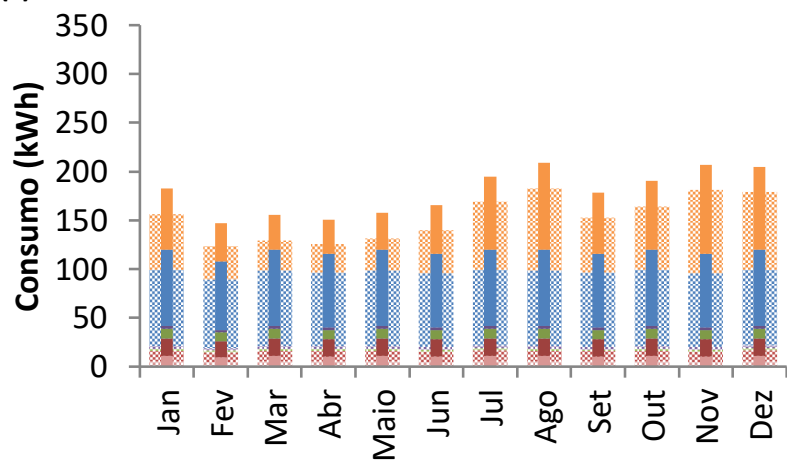

Fonte: Rodrigues, Santos e Carlo (2019).

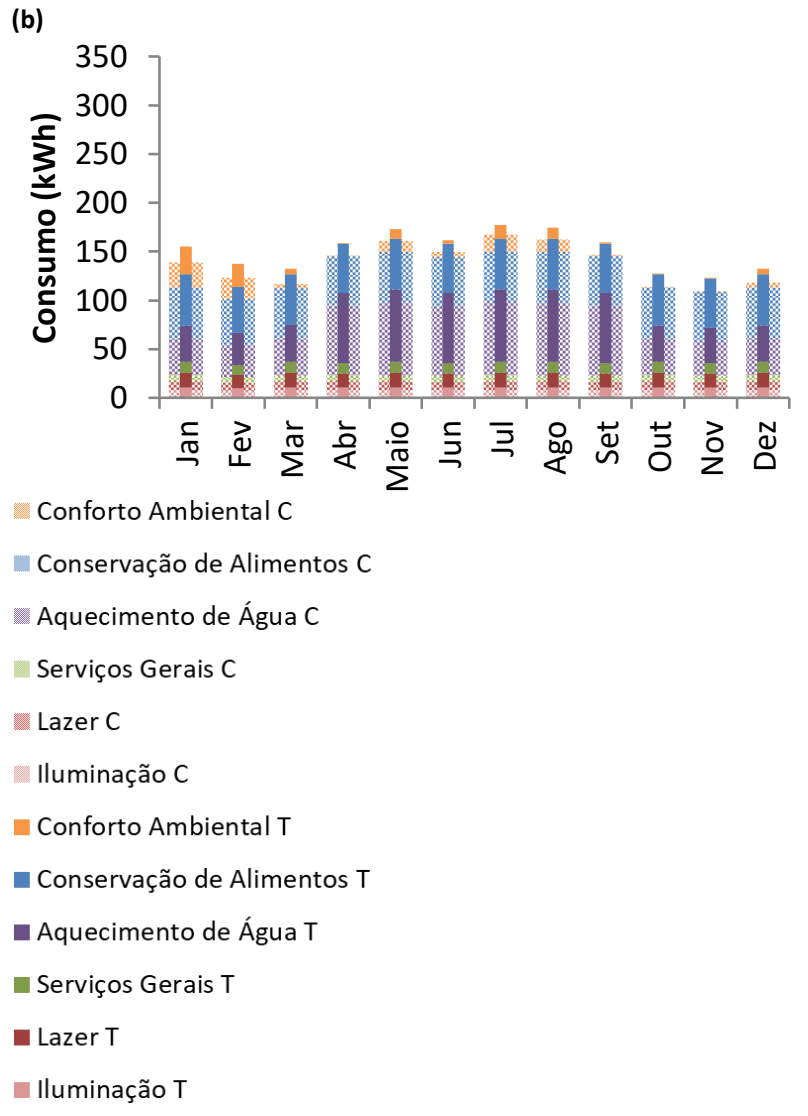

O sistema de geração distribuída fotovoltaica foi inserido nos estilos de vida tradicional e contemporâneo de modelos localizados em três cidades - Bento Gonçalves, São Paulo e Belém, respectivamente zonas bioclimáticas 1, 3 e 8. (Tabela 1). Substituiu-se o sistema de aquecimento de água de elétrico para algum sistema alternativo, como aquecimento solar. O sistema alternativo não foi incluído na simulação. Modelos sem sistemas fotovoltaicos foram também criados, com chuveiros elétricos simulados com potência de 5500 W. Em seguida, realizou-se a simulação do consumo e geração de energia com o programa EnergyPlus 8.7.

\begin{tabular}{|c|c|c|c|}
\hline & $\begin{array}{l}\text { Bento Gonçalves } \\
\text { (ZB1) }\end{array}$ & $\begin{array}{l}\text { São Paulo } \\
\text { (ZB3) }\end{array}$ & $\begin{array}{l}\text { Belém } \\
\text { (ZB8) }\end{array}$ \\
\hline Latitude & $-29^{\circ} 10^{\prime} 17^{\prime \prime}$ & $-23^{\circ} 32^{\prime} 56^{\prime \prime}$ & $-01^{\circ} 27^{\prime} 21^{\prime \prime}$ \\
\hline Longitude & $-51^{\circ} 31^{\prime} 09^{\prime \prime}$ & $-46^{\circ} 38^{\prime} 20^{\prime \prime}$ & $-48^{\circ} 30^{\prime} 16^{\prime \prime}$ \\
\hline Altitude (m) & 640 & 760 & 15 \\
\hline $\begin{array}{c}\text { Temperatura } \\
\text { média anual }\left({ }^{\circ} \mathrm{C}\right)\end{array}$ & 17 & 19 & 26 \\
\hline $\begin{array}{c}\text { Radiação média } \\
\text { anual (Wh/ } / \mathrm{m}^{2} . \text { dia) }\end{array}$ & 4.400 & 5.100 & 5.300 \\
\hline
\end{tabular}

Posteriormente, as tarifas Convencional e Branca foram aplicadas para 96 casos com e sem energia fotovoltaica, de acordo com a Figura 3. 


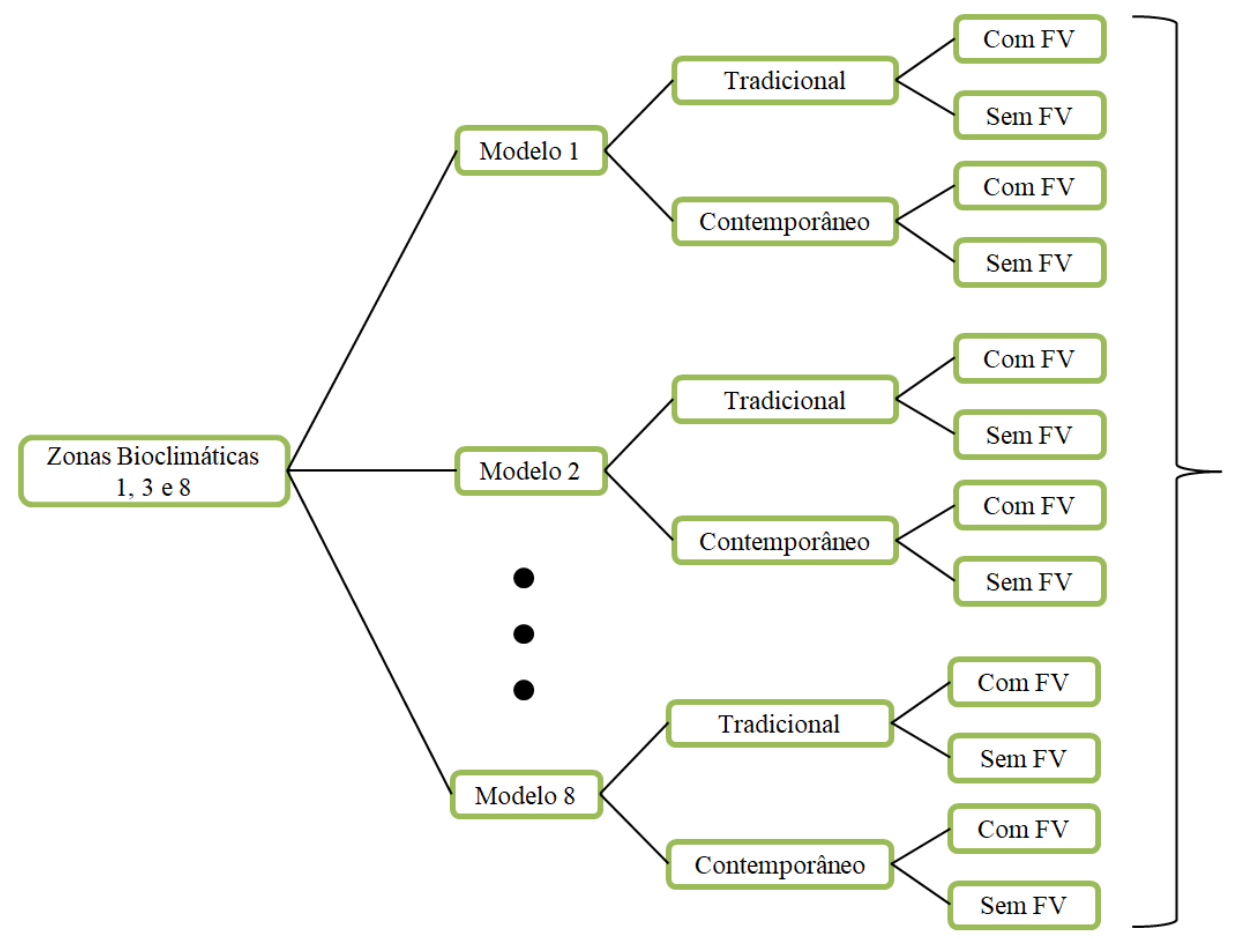

Total de 96 casos simulados, onde foram aplicadas as Tarifas Convencional e Branca, com um total de 192 casos.

Fonte: Elaborado pelos autores.

\section{Inserção do Sistema Fotovoltaico}

Um sistema fotovoltaico de silício policristalino foi inserido nos modelos de unidades habitacionais condicionadas artificialmente após levantamento bibliográfico que definiu a quantidade de módulos e o tipo de tecnologia empregada.

O sistema fotovoltaico foi simulado no formato de kit com número de módulos em função do consumo anual típico de cada modelo de habitação definidos em Rodrigues, Santos e Carlo (2019). Assim, tanto a localidade quanto o estilo de vida aplicados influenciaram diretamente a quantidade de módulos por meio da demanda de energia de cada caso. Sendo assim, a alteração do estilo de vida de tradicional para contemporâneo em um mesmo modelo de habitação alterou o número de módulos em alguns casos.

Para os modelos de unidades habitacionais multifamiliares, que são apartamentos (Modelos 1 ao 5), uma relação da área ocupada pelos kits e da área disponível na cobertura de seu edifício foi criada a fim de determinar o número máximo de sobreposições de cada apartamento e, consequentemente, o número de pavimentos máximos do edifício ao qual este estudo é válido. Foram testados dois cenários: no primeiro toda a área de cobertura $100 \%$ estaria disponível, seguindo o modelo de estrutura proposto por Zomer (2008); e no segundo, apenas $75 \%$ da área estaria disponível, o que deixa uma área disponível para caixa d'água, como visto na Tabela 2.

Cada módulo possui dimensões de 1,9 m², com 1,92 m de comprimento e 0,99 m de largura. O modelo de kit escolhido é da marca Canadian Solar com eficiência média do sistema de $17 \%$. Cada módulo é constituído por 72 células de silício policristalino distribuídas em série. Segundo o fabricante, os valores máximos da potência $(P)$, da tensão (V) e da intensidade (A) de cada painel são, respectivamente, $330 \mathrm{~W}, 47,6 \mathrm{~V}$ e 8,19 A. 
RODRIGUES, Matheus G.; CARLO, Joyce C.

Impactos da geração distribuída fotovoltaica e da tarifa branca no consumo do setor residencial

\begin{tabular}{|c|c|c|c|c|c|c|c|c|c|c|c|c|c|c|c|c|}
\hline \multicolumn{17}{|c|}{ Características dos Modelos } \\
\hline \multirow[b]{2}{*}{$\begin{array}{l}\text { Estilo de } \\
\text { vida }\end{array}$} & \multicolumn{2}{|c|}{ Modelo 1} & \multicolumn{2}{|c|}{ Modelo 2} & \multicolumn{2}{|c|}{ Modelo 3} & \multicolumn{2}{|c|}{ Modelo 4} & \multicolumn{2}{|c|}{ Modelo 5} & \multicolumn{2}{|c|}{ Modelo 6} & \multicolumn{2}{|c|}{ Modelo 7} & \multicolumn{2}{|c|}{ Modelo 8} \\
\hline & C & $\mathbf{T}$ & C & $\mathbf{T}$ & C & $\mathbf{T}$ & C & $\mathbf{T}$ & C & $\mathbf{T}$ & C & $\mathbf{T}$ & C & $\mathbf{T}$ & C & $\mathbf{T}$ \\
\hline Tipo & \multicolumn{2}{|c|}{ Mult. } & \multicolumn{2}{|c|}{ Mult. } & \multicolumn{2}{|c|}{ Mult. } & \multicolumn{2}{|c|}{ Mult. } & \multicolumn{2}{|c|}{ Mult. } & \multicolumn{2}{|c|}{ Uni. } & \multicolumn{2}{|c|}{ Uni. } & \multicolumn{2}{|c|}{ Uni. } \\
\hline $\begin{array}{l}\text { Área Cob. } \\
\qquad\left(\mathrm{m}^{2}\right)\end{array}$ & \multicolumn{2}{|c|}{53,3} & \multicolumn{2}{|c|}{60,8} & \multicolumn{2}{|c|}{66,7} & \multicolumn{2}{|c|}{67,7} & \multicolumn{2}{|c|}{33,2} & \multicolumn{2}{|c|}{30,7} & \multicolumn{2}{|c|}{55,4} & \multicolumn{2}{|c|}{142,9} \\
\hline Dormitórios & \multicolumn{2}{|c|}{2} & \multicolumn{2}{|c|}{2} & & & & & & & & & & & & 3 \\
\hline $\begin{array}{c}\text { Moradores } \\
\text { Renda }\end{array}$ & & & & & & & & & & & & & & & & 4 \\
\hline $\begin{array}{l}\text { Familiar ( } \mathrm{n}^{\circ} \\
\text { s.m.) }\end{array}$ & & & & & & & & & & & & & & & & 10 \\
\hline & & & & & & & ento & onçal & & & & & & & & \\
\hline Consumo & 95 & 118 & 98 & 125 & 107 & 123 & 112 & 124 & 46 & 48 & 87 & 88 & 82 & 86 & 142 & 166 \\
\hline Módulos & 3 & 4 & 3 & 5 & 3 & 5 & 3 & 5 & 2 & 2 & 3 & 3 & 3 & 3 & 6 & 6 \\
\hline Área Kit & 5,7 & 7,6 & 5,7 & 9,5 & 5,7 & 9,5 & 5,7 & 9,5 & 3,8 & 3,8 & 5,7 & 5,7 & 5,7 & 5,7 & 11,4 & 11,4 \\
\hline Pav. (100\%) & 9 & 7 & 10 & 6 & 11 & 7 & 11 & 7 & 8 & 8 & - & - & - & - & - & - \\
\hline Pav. (75\%) & 7 & 5 & 8 & 4 & 8 & 5 & 8 & 5 & 6 & 6 & - & - & - & - & - & - \\
\hline & & & & & & & São & aulo & & & & & & & & \\
\hline Consumo & 79 & 91 & 80 & 93 & 86 & 96 & 99 & 101 & 43 & 47 & 76 & 86 & 76 & 89 & 138 & 162 \\
\hline Módulos & 2 & 2 & 2 & 2 & 2 & 2 & 2 & 2 & 1 & 1 & 2 & 2 & 2 & 2 & 4 & 4 \\
\hline Área Kit & 3,8 & 3,8 & 3,8 & 3,8 & 3,8 & 3,8 & 3,8 & 3,8 & 1,9 & 1,9 & 3,8 & 3,8 & 3,8 & 3,8 & 7,6 & 7,6 \\
\hline Pav. (100\%) & 14 & 14 & 16 & 16 & 17 & 17 & 17 & 17 & 17 & 17 & - & - & - & - & - & - \\
\hline Pav. (75\%) & 10 & 10 & 12 & 12 & 13 & 13 & 13 & 13 & 13 & 13 & - & - & - & - & - & - \\
\hline & & & & & & & & ém & & & & & & & & \\
\hline Consumo & 142 & 166 & 150 & 178 & 114 & 152 & 145 & 164 & 59 & 71 & 91 & 138 & 85 & 119 & 280 & 285 \\
\hline Módulos & 3 & 4 & 4 & 4 & 3 & 4 & 4 & 4 & 2 & 2 & 3 & 3 & 2 & 3 & 6 & 6 \\
\hline Área Kit & 5,7 & 7,6 & 7,6 & 7,6 & 5,7 & 7,6 & 7,6 & 7,6 & 3,8 & 3,8 & 5,7 & 5,7 & 3,8 & 5,7 & 11,4 & 11,4 \\
\hline Pav. (100\%) & 9 & 7 & 8 & 8 & 11 & 8 & 8 & 8 & 8 & 8 & - & - & - & - & - & - \\
\hline Pav. (75\%) & 7 & 5 & 6 & 6 & 8 & 6 & 6 & 6 & 6 & 6 & - & - & - & - & - & - \\
\hline
\end{tabular}

Fonte: Elaborado pelos autores.

Os kits solares fotovoltaicos foram orientados a norte, com inclinação igual à latitude local. As simulações foram realizadas com o modelo de cálculo de sistemas fotovoltaicos do EnergyPlus denominado Equivalent One-Diode (EOD) e com o método Integrated Surface Outside Face (ISOF), onde a temperatura superficial externa do módulo é adotada como a temperatura da célula para correção da eficiência. Segundo Rodrigues e Carlo (2018), este é um dos métodos do EnergyPlus que apresentou resultados mais próximos aos painéis fotovoltaicos reais.

\section{Simulação}

A simulação foi realizada utilizando arquivos climáticos Energyplus Weather Data (EPW) obtidos pelo INMET (2016). Todas as unidades habitacionais tiveram ventilação natural durante o período do dia ( $7 \mathrm{~h}$ às $18 \mathrm{~h}$ ) e condicionamento artificial disponível nos demais horários, porém sua ativação foi definida de acordo com os resultados da simulação. A ventilação natural teve abertura de janelas configurada para o modelo de rede do EnergyPlus conforme o RTQ-R (INMETRO, 2012). O dimensionamento do sistema de condicionamento de ar do tipo bomba de calor foi automático, com eficiência para nível A e com parâmetros de contorno definidos pelo RTQ-R, tal como temperatura de setpoint (INMETRO, 2012). 
Para os casos simulados com painéis fotovoltaicos, foi considerado que aquecedores solares substituíram o chuveiro elétrico, e como não foi feita simulação do sistema de aquecimento solar, sendo apenas retirado o seu consumo energético, foi criado um backup elétrico acionado durante quinze dias no mês com maior nível de nebulosidade na respectiva localização, obtidos a partir de arquivos das normais climatológicas do Instituto Nacional de Meteorologia (NORMAIS CLIMATOLÓGICAS, 1981-2010): outubro em Bento Gonçalves, janeiro em São Paulo e fevereiro em Belém. O sistema não foi calculado, pois o que interessava para o objetivo do trabalho era o consumo elétrico sendo assim foi considerado que o sistema alterativo atendia a demanda de aquecimento, exceto nos dias de acionamento do backup.

As simulações para o ano completo foram realizadas em intervalos de 10 minutos e as temperaturas de solo foram calculadas no módulo slab do EnergyPlus para os modelos de residência unifamiliar (Modelos 6, 7 e 8). Os resultados foram obtidos em frequência horária para a determinação da média de geração e de consumo energético final em cada um dos casos.

O consumo de cada um dos modelos foi definido de acordo com os usos finais para cada uma das categorias: Aquecimento de água, Conservação de alimentos, Condicionamento de ambientes, lluminação, Lazer e Serviços Gerais. Como visto na Figura 2, que mostra o caso do Modelo 1 sem sistema fotovoltaico nas três localidades. É Importante destacar que com sistema fotovoltaico a única categoria que tem seu consumo alterado é a categoria Aquecimento de água, que foi retirado com a substituição do chuveiro elétrico pelo sistema de aquecimento solar.

Como os modos de vida tradicional e contemporâneo, definidos em Rodrigues, Santos e Carlo (2019), foram aplicados em todos os modelos, observou-se, pelas curvas de carga exemplificadas nos modelos 1 e 7 (Figuras 4 a 7) que estas apresentam o mesmo padrão de distribuição ao longo do dia. De fato, os padrões de uso e ocupação apresentam alterações apenas no número de usuários, quantidade e tipos de equipamentos, o que resulta em alterações apenas da demanda dos modelos simulados.

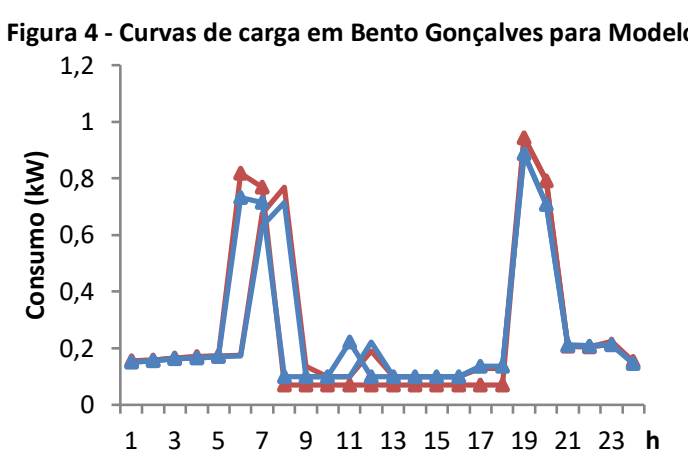

(a)

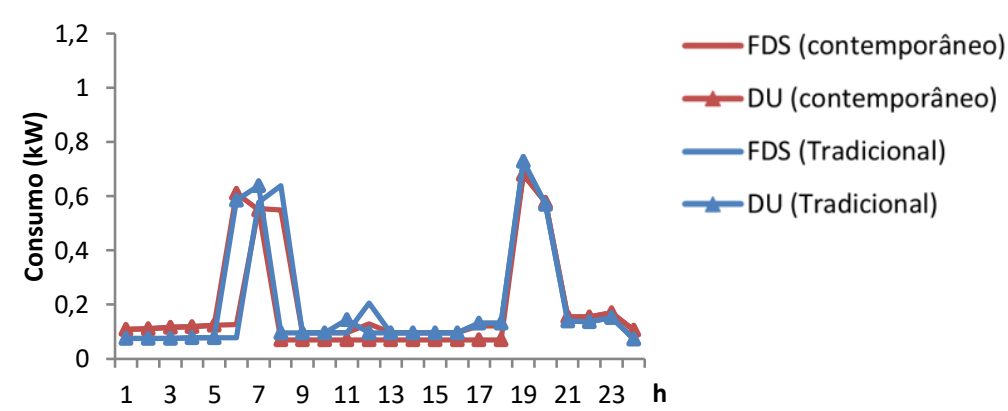

(b)

Fonte: Rodrigues, Santos e Carlo (2019). 
RODRIGUES, Matheus G.; CARLO, Joyce C.

Impactos da geração distribuída fotovoltaica e da tarifa branca no consumo do setor residencial

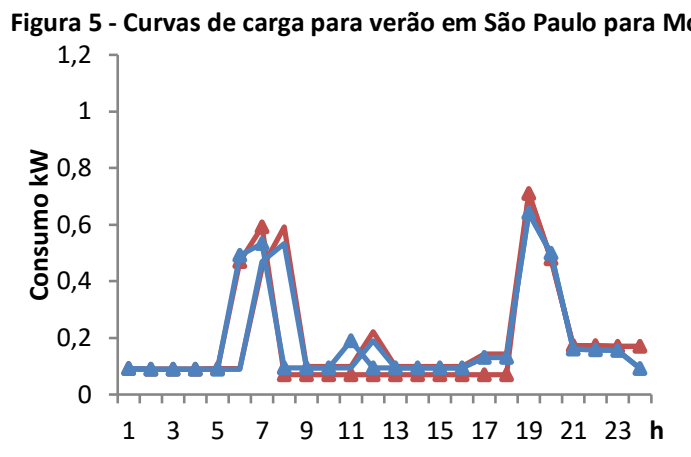

(a)

Fonte: Rodrigues, Santos e Carlo (2019).

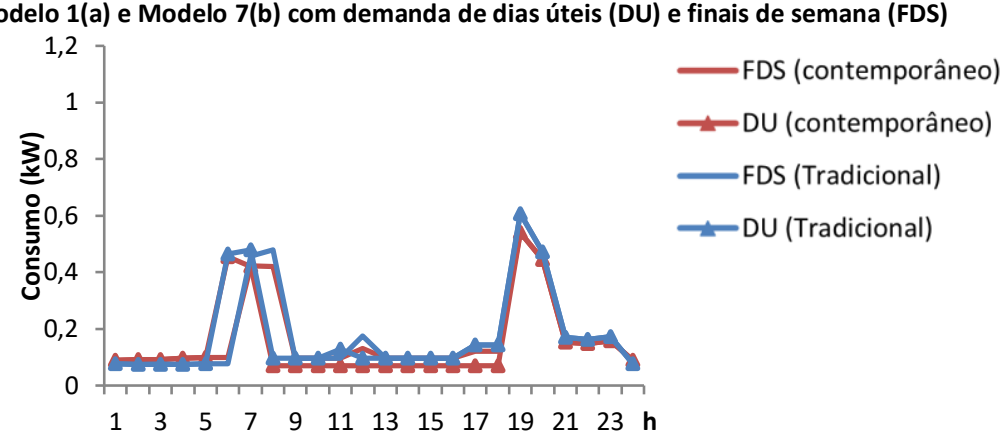

(b)

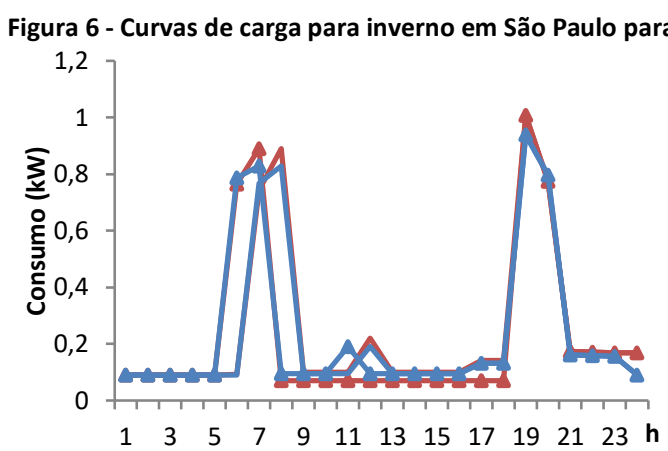

(a)

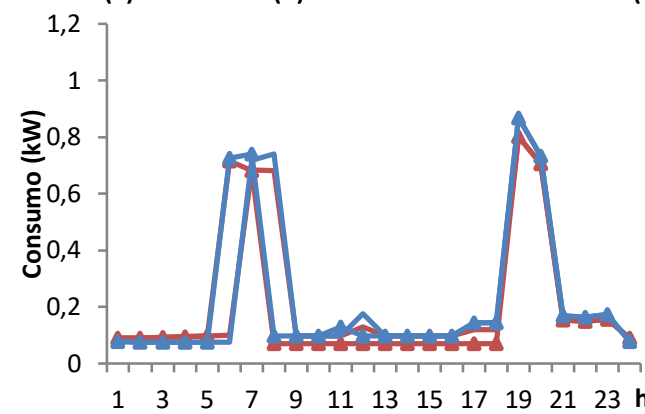

(b)

Fonte: Rodrigues, Santos e Carlo (2019).

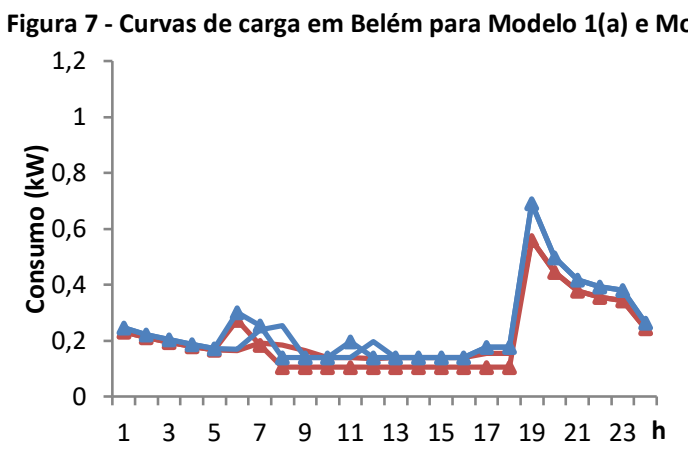

(a)

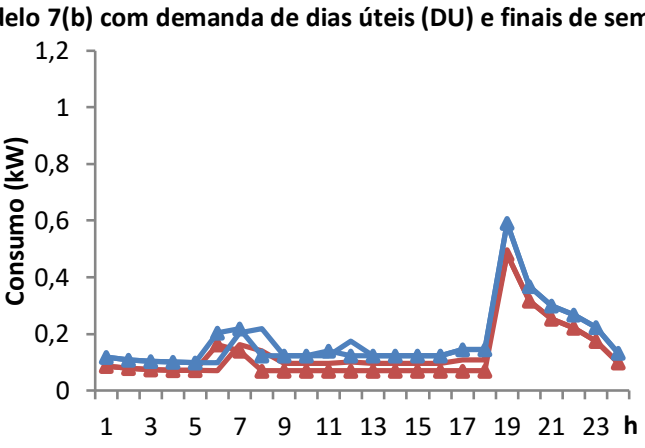

(b)

Fonte: Rodrigues, Santos e Carlo (2019).

Quanto aos modos de vida e seu impacto nas curvas de carga, vale destacar que o Tradicional apresenta como principal diferença para o Contemporâneo o consumo diurno mais alto, nos dias úteis. Quanto aos usos para dias úteis e finais de semana, também se observa duas variações: uma nos horários do início do dia ( 6 h às 9 h), correspondente ao despertar dos usuários e aos picos referentes ao uso do chuveiro, e outra no horário de ocupação da cozinha ( $11 \mathrm{~h}$ e $12 \mathrm{~h}$ ). Já os picos causados pelo uso do chuveiro no início da noite ( $19 \mathrm{~h}$ às $20 \mathrm{~h}$ ) são os mesmos em ambos os modos, porém nos casos com sistema fotovoltaico, os picos gerados pelo uso do chuveiro elétrico deixaram de existir, visto que houve a substituição deste.

\section{Aplicação tarifária}

A aplicação das tarifas incluiu apenas o custo final da energia para o consumidor de cada concessionária, conforme o preço da tarifa de energia (TE) somado ao preço da Tarifa de Uso do Sistema de Distribuição (TUSD): a primeira é relativa ao faturamento mensal 
do consumo de energia enquanto a segunda refere-se ao faturamento mensal de usuários do sistema de distribuição pelo seu uso (ANEEL, 2016b). Impostos não foram incluídos, já que estes se aplicam a ambos os regimes tarifários. Os valores referentes às tarifas foram homologados pela Aneel e apresentados na Resolução Homologatória de cada concessionária para o ano de 2018, para tarifas de aplicação das modalidades Convencional e Horária Branca, para o subgrupo residencial (ANEEL, 2018a, 2018b, 2018c), apresentados na Tabela 3.

Para os casos com geração distribuída, foi necessário observar o custo de disponibilidade que, por definição, é um valor cobrado pelas concessionárias por disponibilizar a energia elétrica no ponto de consumo. O custo de disponibilidade é regulado pela Resolução Normativa $n^{\circ} 414$ (ANEEL, 2010), que estabelece os seguintes valores mínimos de entrega de energia, conforme padrão de conexão com a rede: 30 kWh, se padrão monofásico; 50 kWh, se padrão bifásico; $100 \mathrm{kWh}$, se padrão trifásico. Sendo assim, os valores foram estabelecidos de acordo com as potências de demanda de cada modelo, padrão monofásico apenas para o Modelo 5, trifásico para o Modelo 8 e bifásico para os demais modelos.

\begin{tabular}{|c|c|c|c|c|}
\hline \multicolumn{2}{|c|}{ Zonas Bioclimáticas } & ZB1 & ZB3 & ZB8 \\
\hline \multicolumn{2}{|c|}{ Cidade } & Bento Gonçalves & São Paulo & Belém \\
\hline \multicolumn{2}{|c|}{ Tarifa } & $(\mathrm{R} \$ / \mathrm{kWh})$ & (R\$/kWh) & (R\$/kWh) \\
\hline \multicolumn{2}{|c|}{ Convencional } & 0,528 & 0,484 & 0,000 \\
\hline \multirow{3}{*}{ Branca } & Ponta & 0,932 & 0,865 & 1,361 \\
\hline & Intermediária & 0,601 & 0,562 & 0,877 \\
\hline & Fora de Ponta & 0,422 & 0,412 & 0,554 \\
\hline
\end{tabular}

Fonte: Adaptado das Resoluções 2401, 2380 e 2433 Homologatórias da Aneel (2018a; 2018b; 2018c).

Assim, nos casos em que o consumo mensal foi inferior ao mínimo aplicável, o valor cobrado foi o do custo de disponibilidade, cujo valor correspondeu à quantidade de energia mínima multiplicada pela tarifa Convencional, inclusive nos casos de aplicação da tarifa Branca, conforme determina a Resolução Normativa nº 733 (ANEEL, 2016b).

Análise

Os resultados foram comparados a fim de identificar quais os impactos causados pela inserção da geração distribuída fotovoltaica no consumo energético residencial, combinada à análise da viabilidade da mudança tarifária para a tarifa Branca, para os casos com e sem geração fotovoltaica.

Como há oito modelos para três climas, resultando em 24 edificações a analisar, os modelos 01 e 07 foram selecionados para apresentação da geração fotovoltaica e dos custos tarifários por abrangerem os limites de diferentes condições observadas nos demais modelos. Ademais, eles apresentaram boa diferenciação entre as curvas, o que subsidia a discussão.

\section{Resultados}

Apresentam-se, inicialmente os resultados em uma comparação de consumo e geração sem tarifação. Os resultados tarifados são apresentados posteriormente, para a identificação de quais os casos economicamente mais vantajosos para o consumidor.

\section{Consumo e Geração}

Os consumos e a geração dos modelos de habitação 1 e 7 são apresentados para as três cidades (Figuras 8 a 13). Foi possível observar que, devido ao estilo de vida se repetir nas três localidades e, com isso, os padrões de uso e ocupação não se modificarem, os 
RODRIGUES, Matheus G.; CARLO, Joyce C.

Impactos da geração distribuída fotovoltaica e da tarifa branca no consumo do setor residencial

meses com maior consumo foram aqueles com maior uso do sistema de condicionamento artificial, seja para aquecimento (Bento Gonçalves, Figuras 8 e 9) ou resfriamento (Belém, Figuras 12 e 13). Em contraste, o clima ameno de São Paulo (Figuras 10 e 11) apresenta consumo elevado devido ao sistema de aquecimento de água, que inexiste nas curvas referentes às habitações com sistema FV. Nestas, pode-se observar um pico em janeiro, em que o chuveiro elétrico foi usado por 15 dias.

O balanço pela geração fotovoltaica é, em geral, próximo ao consumo em quase todos os modelos, devido à opção de dimensionamento, com exceção do período de junho a setembro para Bento Gonçalves, devido ao sistema de aquecimento (Figuras 8 e 9).

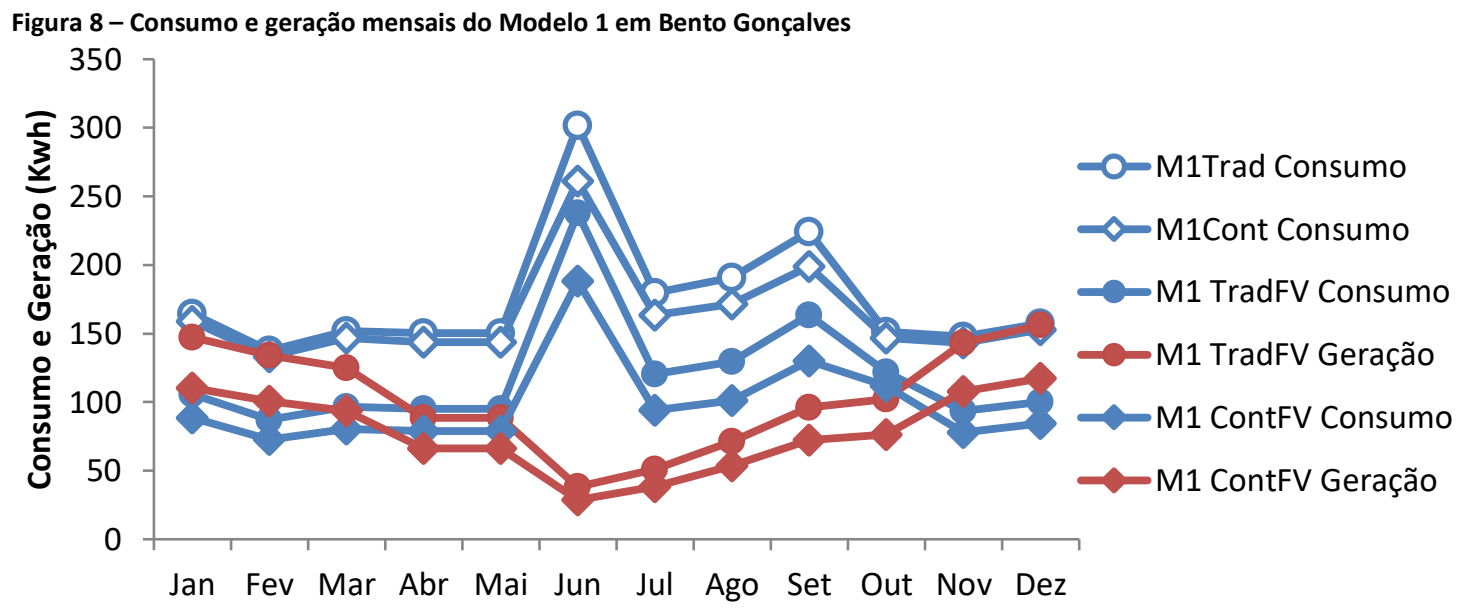
Fonte: os autores.

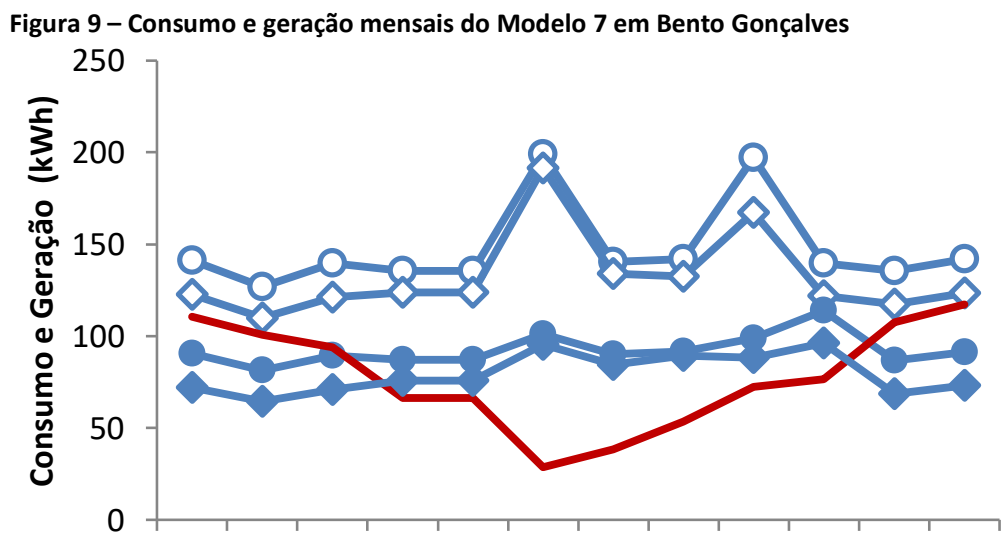

Jan Fev Mar Abr Mai Jun Jul Ago Set Out Nov Dez Fonte: os autores.

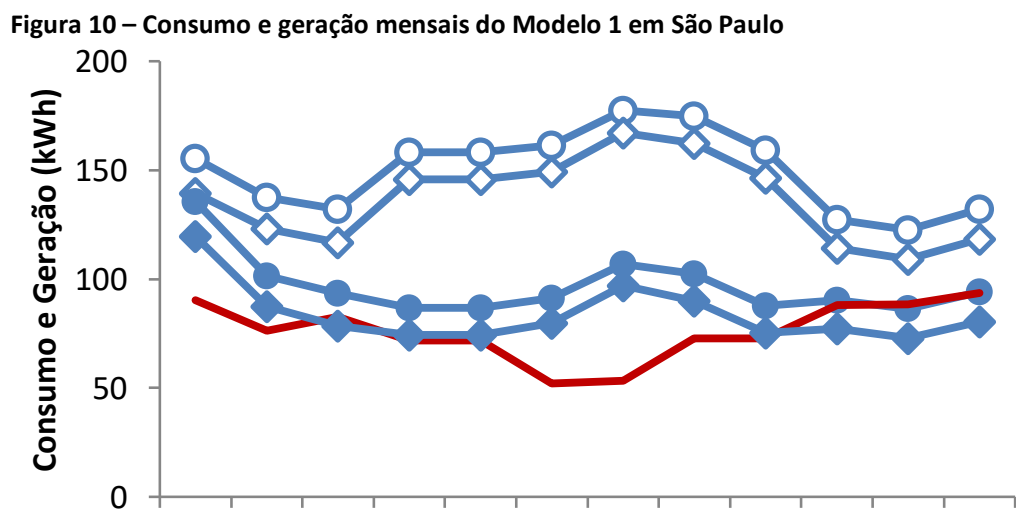

Jan Fev Mar Abr Mai Jun Jul Ago Set Out Nov Dez Fonte: os autores.

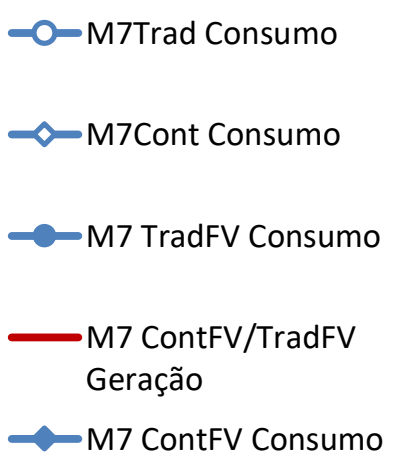

- M1Trad Consumo

$\checkmark$ M1Cont Consumo

-M1 TradFV Consumo

M1ContFV/TradFV Geração

$\sim \mathrm{M} 1$ ContFV Consumo 
RODRIGUES, Matheus G.; CARLO, Joyce C.

Impactos da geração distribuída fotovoltaica e da tarifa branca no consumo do setor residencial

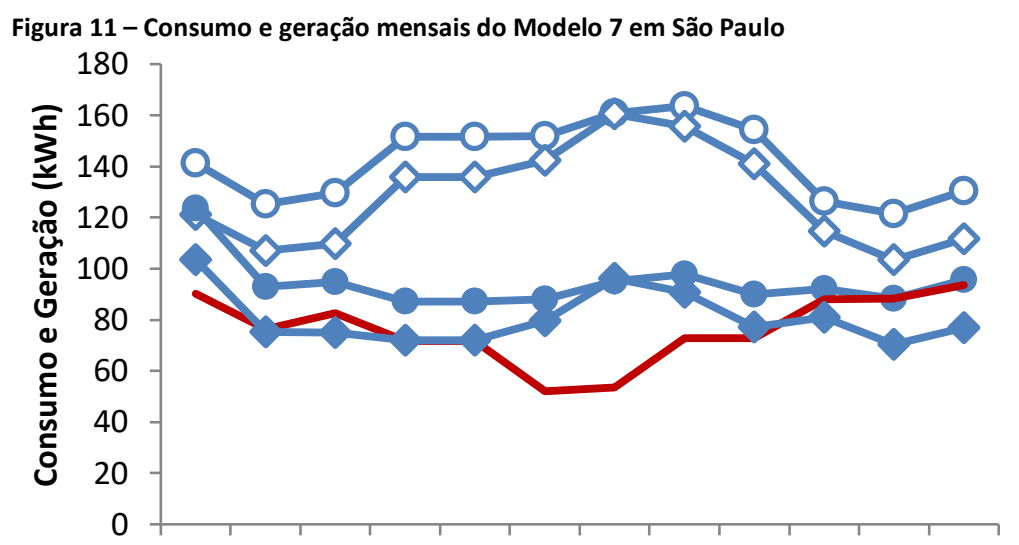

- M7Trad Consumo

$\diamond$ M7Cont Consumo

-M7 TradFV Consumo

M7 ContFV/TradFV

Geração

M7 ContFV Consumo

Jan Fev Mar Abr Mai Jun Jul Ago Set Out Nov Dez

Fonte: os autores.

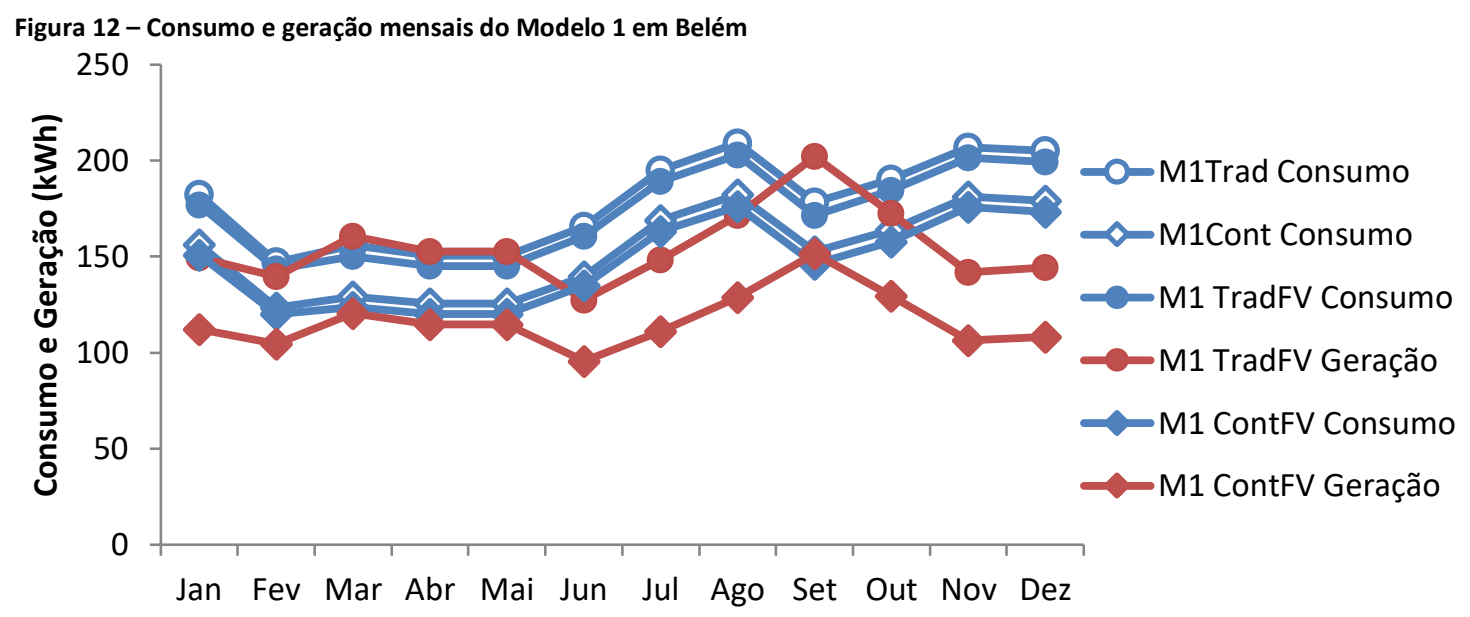

Fonte: os autores.

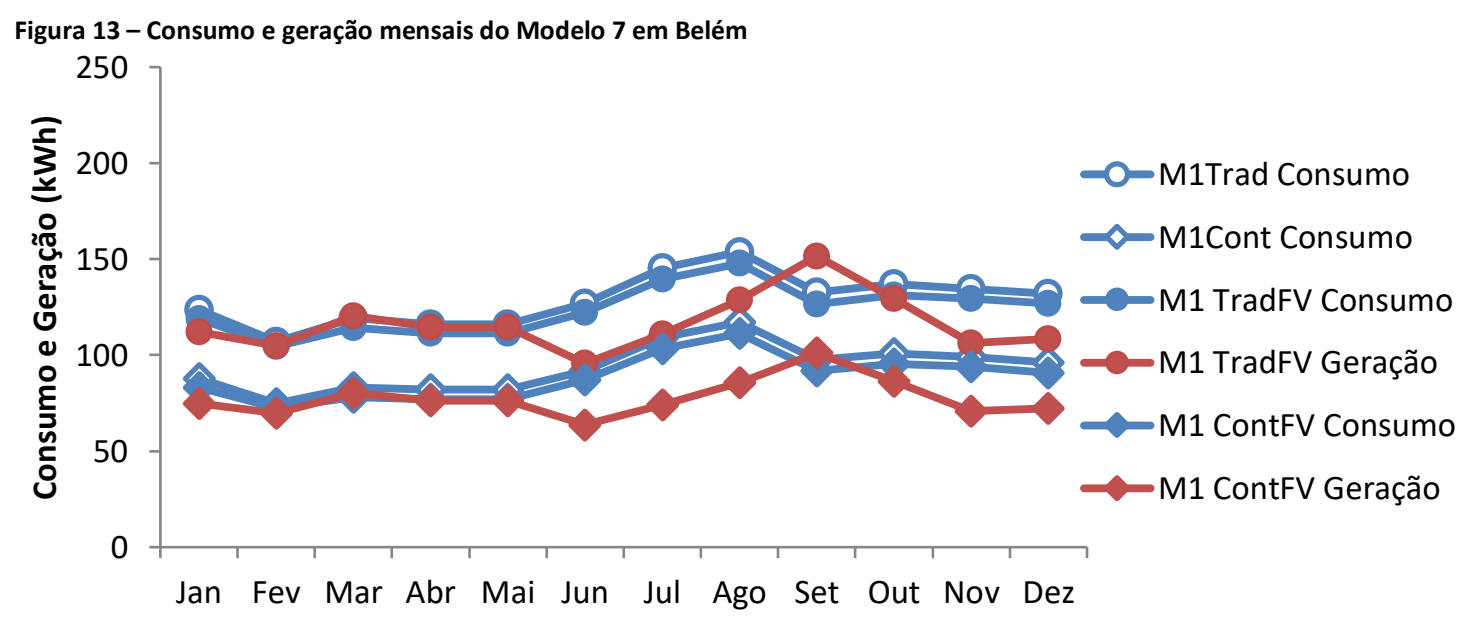

Fonte: os autores.

Como alguns modelos não tiveram diferenças no número de módulos FV quando variado o estilo de vida (vide Tabela 2), os gráficos mostram apenas uma linha correspondente à geração, como pode ser visto nos casos do modelo 7 em Bento Gonçalves (Figura 9), e modelos 1 e 7 em São Paulo (Figuras 10 e 11).

\section{Custo de Energia Elétrica}

A tarifação permitiu identificar que, para todos os casos sem sistema fotovoltaico, a tarifa Convencional foi mais benéfica do ponto de vista financeiro, visto que tanto no 
RODRIGUES, Matheus G.; CARLO, Joyce C.

Impactos da geração distribuída fotovoltaica e da tarifa branca no consumo do setor residencial

estilo Tradicional quanto no Contemporâneo o pico de consumo se concentra exatamente nos horários dos períodos intermediário e de ponta da tarifa Branca (Figuras 14, 15 e 16).

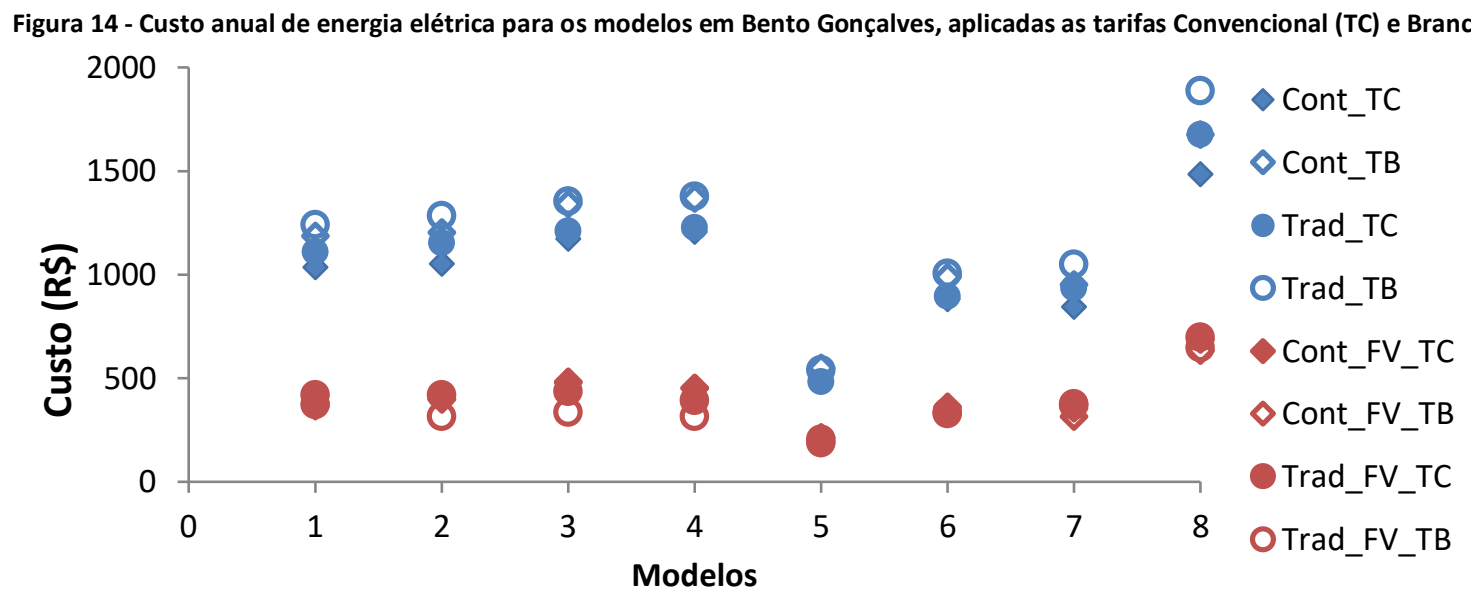

Fonte: os autores.

Figura 15 - Custo anual de energia elétrica para os modelos em São Paulo, aplicadas as tarifas Convencional (TC) e Branca (TB)

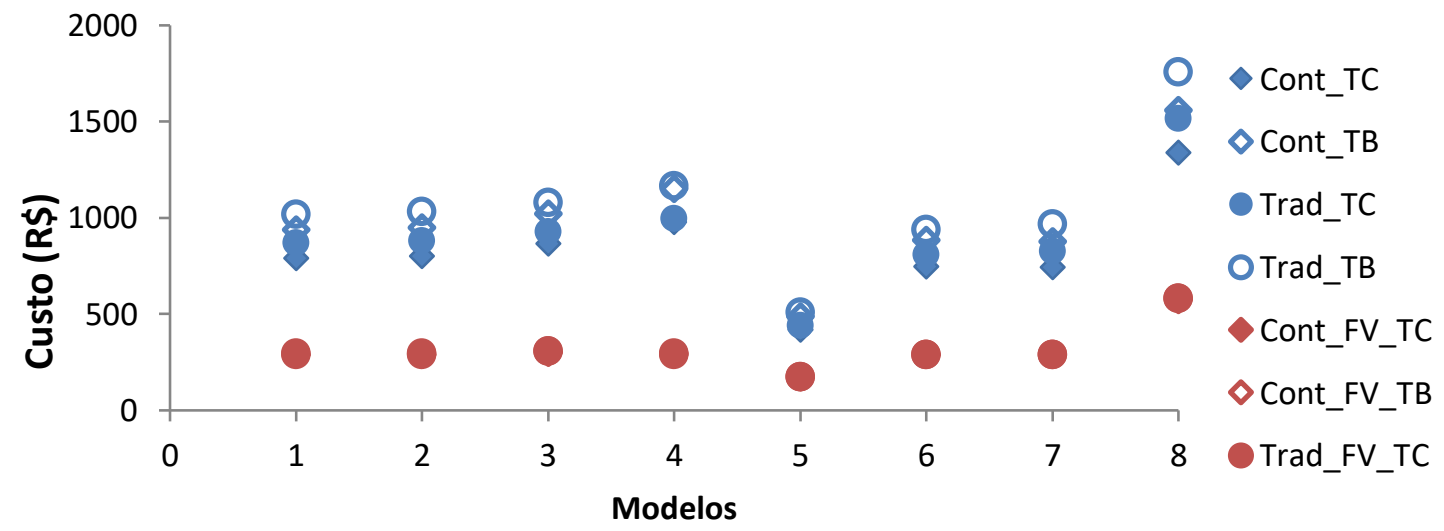

Fonte: os autores.

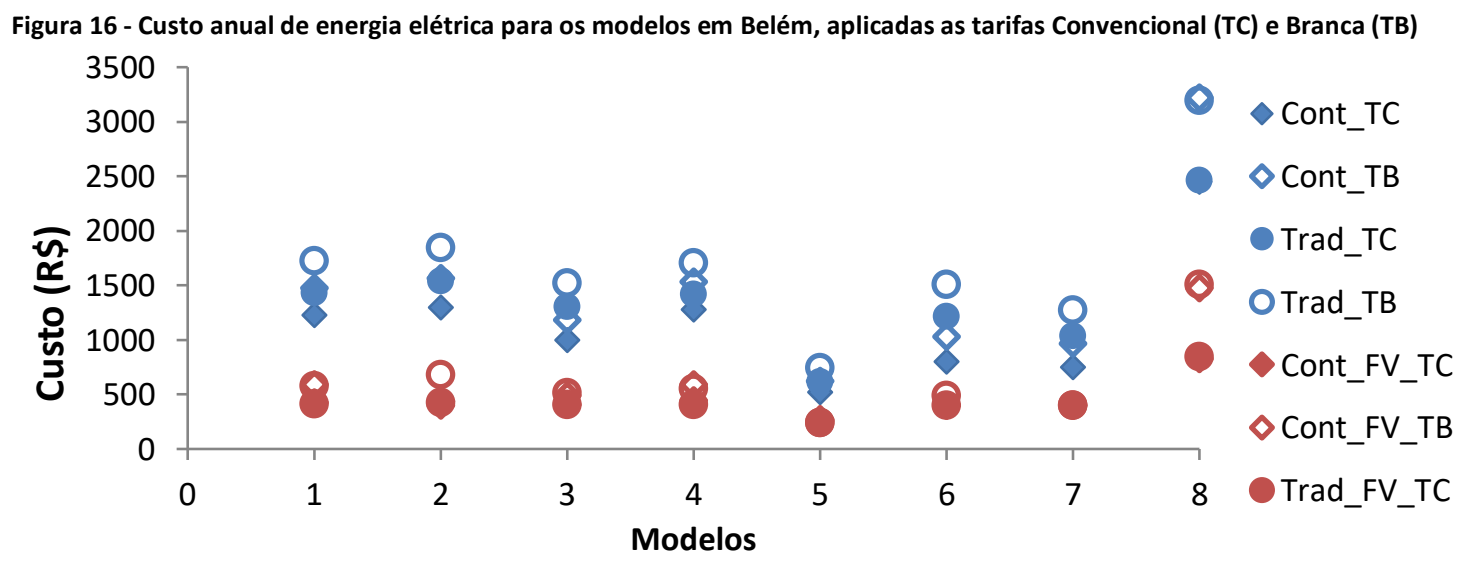

Fonte: os autores.

Para os casos com sistema fotovoltaico, os resultados variaram de acordo com a localidade. Em Bento Gonçalves, a Branca foi economicamente mais vantajosa em cinco dos oito modelos, devido à demanda de energia no período de frio. Nos casos de São Paulo, as duas modalidades tarifárias tiveram os custos finais de energia iguais ou muito próximos, devido à aplicação da taxa de disponibilidade mensal, que é cotada a partir de um preço único independente da modalidade, conforme Resolução Normativa n 733 
(ANEEL, 2016b). Ou seja, a geração fotovoltaica atendeu à demanda das habitações e o preço mínimo referente à taxa de disponibilidade foi aplicado. Em menor número, casos como estes foram também identificados em Bento Gonçalves (Modelos 1, 5 e 6) e Belém (Modelos 5, 7). Em Belém, a tarifa Convencional foi mais benéfica em seis casos (Modelos 1, 2, 3, 4, 6 e 8), devido ao pico de consumo no horário de ponta ser ocasionado pelo ar condicionado.

Em Belém, o pico de consumo das habitações com FV não se alterou com a inserção do sistema FV, pois sua principal causa (condicionamento ambiental) não foi eliminada. Já em São Paulo e Bento Gonçalves o pico foi ocasionado pelo chuveiro elétrico, que foi eliminado das habitações com FV. Além disso, a diferença de preço da energia na tarifa Convencional para do horário de ponta da tarifa Branca em Belém $(R \$ 0,70)$ é quase o dobro dos valores de Bento Gonçalves $(R \$ 0,40)$ e São Paulo $(R \$ 0,40)$.

A adesão à tarifa Branca em habitações sem sistema fotovoltaico gerou aumento de custos de 12,7\%, 17,1\%, 23,4\% em Bento Gonçalves, São Paulo e Belém, respectivamente. Este aumento destaca a necessidade da mudança dos hábitos de consumo, mesmo no estilo de vida contemporâneo, a fim de reduzir o uso da energia nos horários de pico. Já nos casos com inclusão de geração fotovoltaica e eliminação do aquecimento elétrico de água, foram observadas economias financeiras anuais médias em Bento Gonçalves de 35,5\%, em São Paulo de 33,4\% e em Belém de 36,8\%. Estes casos, ao serem analisados frente às modalidades tarifárias, foram majoritariamente mais econômicos com adoção da tarifa Convencional.

A tarifa Branca foi mais econômica do que a Convencional na maioria dos casos em Bento Gonçalves, porém com economias anuais mínimas de $\mathrm{R} \$$ 0,60 e máximas de $\mathrm{R} \$$ 101,00, o que pode ser considerado uma economia pequena, dependendo do perfil familiar. É importante destacar que, nos casos em que a tarifa Branca gerou custos iguais ou inferiores à Convencional, se o usuário se dispuser a mudar seus hábitos, é possível obter maiores economias.

Nas Tabela 4, 5 e 6 são apresentadas as diferenças entre os custos de energia para os dois regimes tarifários.

Tabela 4 - Custos anuais de energia (R\$̣) e médias das diferenças em cada modelo para a cidade de São Paulo

\begin{tabular}{|c|c|c|c|c|}
\hline & & Convencional & Branca & Dif. (TC-TB) \\
\hline \multirow{4}{*}{ Sem FV } & Máx. & 1678,15 & 1887,98 & $-55,65$ \\
\hline & Méd. & 1054,34 & 1188,08 & $-133,74$ \\
\hline & Mín. & 484,24 & 540,20 & $-209,82$ \\
\hline & Desvio P. & 310,20 & 349,61 & 40,56 \\
\hline \multirow{4}{*}{ Com FV } & Máx. & 699,54 & 648,42 & 101,60 \\
\hline & Méd. & 413,45 & 378,69 & 34,76 \\
\hline & Mín. & 206,45 & 189,93 & $-6,56$ \\
\hline & Desvio $\mathrm{P}$. & 131,87 & 127,58 & 35,40 \\
\hline
\end{tabular}

Fonte: os autores.

Tabela 5 - Custos anuais de energia (R\$) e médias das diferenças em cada modelo para a cidade de Bento Gonçalves

\begin{tabular}{|c|c|c|c|c|}
\hline & & Convencional & Branca & Dif. (TC-TB) \\
\hline \multirow{4}{*}{ Sem FV } & Máx. & 1513,58 & 1758,62 & $-68,34$ \\
\hline & Méd. & 871,37 & 1020,75 & $-149,38$ \\
\hline & Mín. & 418,34 & 486,68 & $-245,03$ \\
\hline & Desvio P. & 270,83 & 314,63 & 44,24 \\
\hline \multirow{4}{*}{ Com FV } & Máx. & 580,36 & 580,36 & 8,43 \\
\hline & Méd. & 314,75 & 313,27 & 1,48 \\
\hline & Mín. & 174,11 & 174,11 & $-3,26$ \\
\hline & Desvio P. & 111,39 & 110,28 & 3,04 \\
\hline
\end{tabular}


RODRIGUES, Matheus G.; CARLO, Joyce C.

Impactos da geração distribuída fotovoltaica e da tarifa branca no consumo do setor residencial

Tabela 6 - Custos anuais de energia (R\$̣) e médias das diferenças em cada modelo para a cidade de Belém

\begin{tabular}{ccccc}
\hline \multirow{4}{*}{ Sem FV } & & Convencional & Branca & Dif. (TC-TB) \\
\cline { 2 - 4 } & Máx. & 2460,90 & 3221,01 & $-98,06$ \\
\cline { 2 - 4 } & Méd. & 1271,72 & 1569,09 & $-297,36$ \\
\cline { 2 - 4 } & Mín. & 522,26 & 620,32 & $-772,27$ \\
\cline { 2 - 4 } Com FV & Desvio P. & 550,04 & 729,37 & 187,08 \\
\cline { 2 - 4 } & Máx. & 843,78 & 1510,60 & 0,00 \\
\cline { 2 - 4 } & Méd. & 445,10 & 601,78 & $-156,68$ \\
\cline { 2 - 4 } & Mín. & 241,55 & 241,55 & $-666,82$ \\
\hline
\end{tabular}

Fonte: os autores.

Nos casos onde a tarifa Branca cumpre o seu propósito de ser uma alternativa econômica para o consumidor, é importante destacar que o pico de consumo nos horários intermediário e de ponta foi eliminado, com a substituição do sistema elétrico de aquecimento de água, sem comprometimento do conforto residencial ou dos hábitos. Porém, nos outros casos, observou-se que, somente com a substituição do sistema elétrico de aquecimento de água, a adoção da tarifa Branca não traz benefícios ao consumidor sem que seus hábitos de consumo sejam comprometidos. Esta última condição poderá interferir no conforto do usuário em sua residência.

\section{Conclusão}

Este trabalho apresentou uma análise do impacto da geração distribuída fotovoltaica e da tarifa Branca no custo da energia elétrica para usuários do setor residencial, a partir da simulação de modelos de unidades habitacionais com usuários com modos de vida contemporâneo e tradicional. $O$ estudo gerou um total de 96 modelos simulados onde foram aplicadas as duas modalidades tarifárias, Convencional e Branca, contabilizando 192 casos analisados.

A adoção de kits fotovoltaicos se mostrou eficaz para alcançar o consumo mínimo referente à taxa de disponibilidade do sistema, embora muitos casos não apresentaram excedente de geração para acúmulo de créditos de energia nos meses subsequentes. Contudo, é importante destacar que, na maioria dos casos com uso do sistema fotovoltaico, a opção de regime tarifário se mostra indiferente, visto que na maioria dos meses a cobrança é do custo de disponibilidade, que é baseado no preço da tarifa Convencional, gerando, assim, custos muito próximos ou iguais entre as duas tarifas. $\mathrm{O}$ sistema de aquecimento solar de água mostrou ter impacto direto nos resultados de custo de energia pois, com a substituição do sistema nos locais onde o chuveiro elétrico era o maior responsável pelo pico no horário de ponta, a tarifa financeiramente mais econômica passou a ser a tarifa Branca.

A análise das modalidades tarifárias mostrou que a tarifa Branca foi inviável nas habitações sem sistema fotovoltaico para os três climas analisados, porém com variações em relação ao modo de vida tradicional ou contemporâneo e ao modelo de habitação. Nos casos com sistema fotovoltaico, em Bento Gonçalves, onde a demanda por aquecimento de água é maior, a tarifa Convencional foi mais benéfica. Deve-se lembrar que estes modelos tiveram chuveiros elétricos substituídos por sistema alternativo. Em São Paulo, não houve diferenças de custo de acordo com a tarifa, pois o sistema fotovoltaico supriu o consumo até o mínimo necessário para aplicação da taxa de disponibilidade do sistema. Em Belém, onde o aquecimento de água é menos necessário e a demanda pelo condicionamento ambiental é maior, a substituição do chuveiro elétrico por um outro sistema de aquecimento de água não foi impactante. 
Assim, não houve benefício na adoção da tarifa Branca em seis dos oito modelos de habitação analisados.

Os resultados mostraram que o condicionamento ambiental e o aquecimento de água interferiram nos benefícios decorrentes da modalidade tarifária, variando conforme o uso da habitação. Por consequência, mostraram como o clima impacta na escolha tarifária. Em diversos casos, a adoção de um sistema fotovoltaico alterou os benefícios decorrentes da nova modalidade tarifária devido à geração de energia combinada à substituição do chuveiro elétrico, enquanto em outros o consumo mínimo referente à taxa de disponibilidade igualou as possibilidades.

Deve-se destacar que estes casos foram analisados com hábitos de consumo típicos, sejam no modelo Tradicional ou no Contemporâneo e, portanto, sem mudança nos hábitos dos usuários.

\section{Agradecimentos}

À Coordenaç̧ão de Aperfeiçoamento de Pessoal de Nível Superior (CAPES), e à Companhia Energética de Minas Gerais (Cemig-D) e ao Programa de Pesquisa e Desenvolvimento Tecnológico - P\&D regulado pela Aneel, no âmbito do projeto "D0638 - Análise da Viabilidade da Energia Fotovoltaica no Brasil em Face do Marco Regulatório da Geração Distribuída no Setor Elétrico Brasileiro - Aneel RN 482/12", coordenado pela Universidade Federal de Viçosa em parceria com a Pontifícia Universidade Católica de Minas Gerais. pelo financiamento da pesquisa.

\section{Referências}

ABRAHÃO, K. C. F. Avaliação dos pesos regionais do RTQ-R a partir da análise da estrutura do consumo residencial de energia elétrica por região geográfica. 2015. 244f. Dissertação (Mestrado) - Programa de Pós-graduação em Ambiente Construído e Patrimônio Sustentável. Universidade Federal de Minas Gerais, Belo Horizonte, 2015.

ANEEL. Micro e Minigeração Distribuída Sistema de Compensação de Energia Elétrica. 2. ed. Brasília: ANEEL, $2016 a$. (Cadernos temáticos ANEEL). Disponível em https://www.aneel.gov.br/livros/-

lasset_publisher/NBC33JHYPjrv/content/cadernos-tematicos-aneel-micro-e-minigeracao-distribuida-2edicao/656835. Acesso em: 17 ago. 2018.

ANEEL. Resolução Homologatória n 2380 de 2018: homologa o resultado da quarta Revisão Tarifária Periódica - RTP da Energisa Mato Grosso do Sul Distribuidora de Energia S.A. - EMS, as Tarifas de Energia - TE e as Tarifas de Uso do Sistema de Distribuição - TUSD, e dá outras providências. Brasília: ANEEL, 2018a. 12 p., il. Disponível em: http://www2.aneel.gov.br/cedoc/reh20182380ti.pdf. Acesso em: 24 set. 2018.

ANEEL. Resolução Homologatória n 2400 de 2018: homologa o resultado da quarta Revisão Tarifária Periódica RTP da Rio Grande Energia S/A. - RGE, as Tarifas de Energia - TE e as Tarifas de Uso do Sistema de Distribuição TUSD, e dá outras providências. Brasília: ANEEL, 2018b. 8 p., il. Disponível em:

http://www2.aneel.gov.br/cedoc/reh20182400ti.pdf. Acesso em: 24 set. 2018.

ANEEL. Resolução Homologatória n 2433 de 2018 Homologa o resultado do Reajuste Tarifário Anual de 2018, as Tarifas de Energia - TE e as Tarifas de Uso do Sistema de Distribuição - TUSD referentes à Centrais Elétricas do Pará S/A. - Celpa, e dá outras providências. Brasília: ANEEL, 2018c. 8 p., il. Disponível em: http://www2.aneel.gov.br/cedoc/reh20182433ti.pdf. Acesso em: 24 set. 2018.

ANEEL. Resolução Normativa n 414/2010: condições gerais de fornecimento de energia elétrica. [Brasília]: ANEEL, [2010?]. 206 p., il. Disponível em: http://www2.aneel.gov.br/cedoc/bren2010414.pdf. Acesso em: 18 nov. 2018.

ANEEL. Resolução Normativa n 687/2015: Altera a Resolução Normativa n 482, de 17 de abril de 2012, e os Módulos 1 e 3 dos Procedimentos de Distribuição - PRODIST. Brasília: ANEEL, 2015. 206 p., il. Disponível em:

https://www2.aneel.gov.br/cedoc/ren2015687.pdf. Acesso em: 17 ago. 2018. 
ANEEL. Resolução Normativa n 733 de 2016: estabelece as condições para a aplicação da modalidade tarifária horária branca. Brasília: ANEEL, 2016b. 4 p., il. Disponível em: http://www2.aneel.gov.br/cedoc/ren2016733.pdf. Acesso em: 17 ago. 2018.

DRUDE, L.; PEREIRA JUNIOR, L.C.; RÜTHER, R. Photovoltaics (PV) and electric vehicle to-grid (V2G) strategies for peak demand reduction in urban regions in Brazil in a smart grid environment. Renewable Energy, v. 68, p. 443-451, 2014. DOI:https://doi.org/10.1016/j.renene.2014.01.049

FINOTTI, A. S.; ALMEIDA, M. P.; ZILLES, R. Simulação Do Uso De Baterias Adotando A Tarifa Branca Para Microgeração Fotovoltaica De Classe Residencial. In: Congresso Brasileiro de Energia Solar, 7., 2018, Gramado. Anais... Gramado, CBENS, 2018.

INMETRO - INSTITUTO NACIONAL DE METROLOGIA QUALIDADE E TECNOLOGIA. Regulamento Técnico da Qualidade para o Nível de Eficiência Energética de Edificações Residenciais. Anexo da Portaria INMETRO no. 18, de janeiro de 2012 que aprova a revisão do Regulamento Técnico da Qualidade - RTQ para o Nível de Eficiência Energética de Edificações Residenciais. Rio de Janeiro, 2012. Disponível em: http://www.pbeedifica.com.br/sites/default/files/projetos/etiquetagem/residencial/downloads/RTQR.pdf. Acesso em: 2 jul. 2018.

NORMAIS CLIMATOLÓGICAS. Clima. In: INSTITUTO NACIONAL DE METEOROLOGIA. INMET Normais Climatológicas do Brasil, DF: INMET, [1981-a 2010]. Disponível em: https://portal.inmet.gov.br/normais/. Acesso em: 9 nov. 2018.

IEA - INTERNATIONAL ENERGY AGENCY. Renewable 2019: Analysis and forecasts to 2024. Paris: IEA, 2019. (Market Report Series). Disponível em https://www.iea.org/reports/renewables-2019/distributed-solar-pv\#abstract. Acesso em: 17 set. 2020.

JANNUZZI, G. M.; MELO, C. A. Grid-connected photovoltaic in Brazil: Policies and potential impacts for 2030. Energy for Sustainable Development. v. 17, p. 40-46, 2013. DOI:https://doi.org/10.1016/j.esd.2012.10.010

MIRANDA, R. F. C.; SZKLO, A.; SCHAEFFER, R. Sistemas Fotovoltaicos Acoplados A Baterias No Setor Residencial Sob O Âmbito Da Tarifa Branca De Energia. In: Congresso Brasileiro de Energia Solar, 52014 Recife. Anais... Recife, CBENS, 2014.

PONCE-JARA, M.A.; RUIZ, E.; GIL, R.; SANCRISTÓBAL, E.; PÉREZ-MOLINA, C.; CASTRO, M. Smart Grid: Assessment of the past and present in developed and developing countries. Energy Strategy Reviews, v. 18, p. 38-52, 2017.

VASCONCELLOS, L.E.M.; LIMBERGER, M.A.C. (Org.). Energia solar para aquecimento de água no Brasil: contribuições da Eletrobrás Procel e parceiros. Rio de Janeiro: Eletrobrás, 2012.

REN21 - RENEWABLE ENERGY POLICY NETWORK FOR THE 21ST CENTURY. Renewables 2019 Global Status Report. Paris: REN21 Secretariat. 2017. Disponível em https://www.ren21.net/wp-

content/uploads/2019/05/gsr_2019_full_report_en.pdf. Acesso em: 17set. 2020.

RODRIGUES, T. T.; CARLO, J. C. Modelagem térmica de fotovoltaicos semitransparentes: impactos na eficiência da célula e no desempenho da zona. PARC - Pesquisa em Arquitetura e Construção. v.9, n.4. p.305-318. 2018. DOI:https://doi.org/10.20396/parc.v9i4.8652785

RODRIGUES, M. G.; SANTOS, D. M. dos; CARLO, J. C. Simulação energética de unidades habitacionais baseada em usuários com modos de vida contemporâneo e tradicional. Cadernos PROARQ. v.33, p. 154-177. 2019. DOI:https://doi.org/10.37180/2675-0392-n33-8

SANTOS, I. P.; RÜTHER, R. The potential of building-integrated (BIPV) and building-applied photovoltaics (BAPV) in single-family, urban residences at low latitudes in Brazil. Energy and Buildings. v.50, p. 290-297, 2012. DOI:https://doi.org/10.1016/j.enbuild.2012.03.052

SOUTO, O. C. N.; SILVA, S. B.; VIAJANTE, G. P.; SOUZA, D. M.; AMARAL, J. F. S. Análise econômica de sistemas fotovoltaicos conectados à rede considerando a tarifa branca e ações de eficiência energética para consumidores 
RODRIGUES, Matheus G.; CARLO, Joyce C.

Impactos da geração distribuída fotovoltaica e da tarifa branca no consumo do setor residencial

residenciais utilizando Homer Pro Energy. In: CONGRESSO BRASILEIRO DE ENERGIA SOLAR, 7., 2018, Gramado. Anais... Gramado, CBENS, 2018.

TEIXEIRA, C. A.; INVIDIATA, A.; SORGATO, M. J.; MELO, A. P.; FOSSATI, M. LAMBERTS, R. Levantamento das características de edifícios residenciais brasileiros. Relatório Centro Brasileiro de Eficiência Energética em Edificações-CB3E, Florianópolis, 2015.

TELLES, C. P. Proposta de simplificação do RTQ-R. Dissertação (Mestrado) - Centro de ciências Exatas e Tecnológicas, Programa de Pós-Graduação em Arquitetura e Urbanismo, Universidade Federal de Viçosa, Viçosa, 2016.

TENFEN, D.; LEMOS, F. A. B.; FERNANDES, R. C.; DECKER, I. C. Microgrids and Microgeneration in Brazilian Energy Market: a Discussion of Regulatory and Commercial Aspects. In: Latin-American Congress On Electricity Generation And Transmission, 9., 2013, Viña del Mar, Chile. Anais... Chile, CLAGTEE, 2013.

VIANA, M. S.; MANASSERO JUNIOR, G.; UDAETA, M. E. M. Analysis of demand response and photovoltaic distributed generation as resources for power utility planning. Applied Energy. v. 217, p. 456-466, 2018. DOI:ttps://doi.org/10.1016/j.apenergy.2018.02.153

ZOMER, Clarissa Debiazi. Usina Solar Fotovoltaica Integrada A Uma Edificação Urbana: O Maior Gerador Solar Do Hemisfério Sul. In: Instituto Ideal. (Org.). Eco-Lógicas: renovar é pensar diferente. 1ed. Florianópolis, 2008, p. 91106.

\section{${ }^{1}$ Matheus Gomes Rodrigues}

Arquiteto e Urbanista. Mestrando no Programa de Pós-Graduação em Arquitetura e Urbanismo. Universidade Federal de Viçosa, Departamento de Arquitetura e Urbanismo. Endereço postal: Avenida P. H. Rolfs, s/n, Campus UFV, Viçosa, MG, Brasil, 36570-900.

\section{Joyce Correna Carlo}

Arquiteta e Urbanista. Doutora. Professora da UFV. Universidade Federal de Viçosa, Departamento de Arquitetura e Urbanismo. Endereço postal: Avenida P. H. Rolfs, s/n, Campus UFV, Viçosa, MG, Brasil, 36570-900. 